\title{
Functional Identification and Characterization of the Brassica Napus Transcription Factor Gene BnAP2, the Ortholog of Arabidopsis Thaliana APETALA2
}

\author{
Xiaohong Yan ${ }^{19}$, Lei Zhang ${ }^{29}$, Bo Chen ${ }^{19}$, Zhiyong Xiong ${ }^{3}$, Chunli Chen ${ }^{4}$, Lijun Wang ${ }^{1}$, Jingyin Yu ${ }^{1}$, \\ Changming $\mathrm{Lu}^{1 *}$, Wenhui Wei ${ }^{1 *}$
}

1 Key Laboratory of Oil Crop Biology and Genetic Breeding of the Ministry of Agriculture, Institute of Oil Crops, Chinese Academy of Agricultural Sciences, Wuhan, China, 2 School of Life Sciences, Wuhan University, Wuhan, China, 3 Division of Biological Sciences, University of Missouri-Columbia, Columbia, Missouri, United States of America, 4 National Key Laboratory of Crop Genetic Improvement, School of Life Sciences and Technology, Huazhong Agricultural University, Wuhan, China

\begin{abstract}
BnAP2, an APETALA2 (AP2)-like gene, has been isolated from Brassica napus cultivar Zhongshuang 9. The cDNA of BnAP2, with 1, $299 \mathrm{bp}$ in length, encoded a transcription factor comprising of 432 amino acid residues. Results from complementary experiment indicated that BnAP2 was completely capable of restoring the phenotype of Arabidopsis ap2-11 mutant. Together with the sequence and expression data, the complementation data suggested that $B n A P 2$ encodes the ortholog of AtAP2. To address the transcriptional activation of BnAP2, we performed transactivation assays in yeast. Fusion protein of BnAP2 with GAL4 DNA binding domain strongly activated transcription in yeast, and the transactivating activity of BnAP2 was localized to the N-terminal 100 amino acids. To further study the function of BnAP2 involved in the phenotype of $B$. napus, we used a transgenic approach that involved targeted RNA interference (RNAi) repression induced by inp-RNA. Floral various phenotype defectives and reduced female fertility were observed in B. napus BnAP2-RNAi lines. Loss of the function of $B \cap A P 2$ gene also resulted in delayed sepal abscission and senescence with the ethylene-independent pathway. In the strong BnAP2-RNAi lines, seeds showed defects in shape, structure and development and larger size. Strong BnAP2RNAi and wild-type seeds initially did not display a significant difference in morphology at $10 \mathrm{DAF}$, but the development of BnAP2-RNAi seeds was slower than that of wild type at $20 \mathrm{DAF}$, and further at $30 \mathrm{DAF}$, wild-type seeds were essentially at their final size, whereas BnAP2-RNAi seeds stopped growing and developing and gradually withered.
\end{abstract}

Citation: Yan X, Zhang L, Chen B, Xiong Z, Chen C, et al. (2012) Functional Identification and Characterization of the Brassica Napus Transcription Factor Gene BnAP2, the Ortholog of Arabidopsis Thaliana APETALA2. PLoS ONE 7(3): e33890. doi:10.1371/journal.pone.0033890

Editor: Baohong Zhang, East Carolina University, United States of America

Received October 20, 2011; Accepted February 18, 2012; Published March 27, 2012

Copyright: ( 2012 Yan et al. This is an open-access article distributed under the terms of the Creative Commons Attribution License, which permits unrestricted use, distribution, and reproduction in any medium, provided the original author and source are credited.

Funding: This work was supported by the National Natural Science Foundation of China (grant no. 30671312), the Natural Science Foundation of Hubei Province (grants no. 2008CDA083 and 2009CDB191), the Chenguang Program of Wuhan City (grant no. 201050231022), the National Nonprofit Institute Research Grant (grant no. 1610172008004), and the Open Program of the Key Laboratory of Oil Crop Biology, Ministry of Agriculture (grants no. 201003 and 201004). The funders had no role in study design, data collection and analysis, decision to publish, or preparation of the manuscript.

Competing Interests: The authors have declared that no competing interests exist.

*E-mail: cmlu@oilcrops.cn (CL); whwei@oilcrops.cn (WW)

9 These authors contributed equally to this work.

\section{Introduction}

Flower is the most important organ of a flowering plant. As a close relative of Arabidopsis thaliana, Brassica napus has equally a concentric arrangement of four types of flower organs: four sepals in whorl 1 , four petals in whorl 2 , six stamens in whorl 3 , and two fused carpels in whorl 4. Floral organ identity is specified by the transcription factors encoded by 3 classes of floral homeotic genes: the A, B and C functional genes [1-3]. Class A genes specify sepals and also interact with class $\mathrm{B}$ genes to specify petals. Class $\mathrm{C}$ genes specify carpels and also interact with class $\mathrm{B}$ genes to specify stamens. Classes A and C genes act antagonistically to restrict each other's activities in perianth and reproductive organs respectively.

APETALA2 (AP2) gene is one of the primary members of class $\mathrm{A}$ genes in Arabidopsis, characterized by the AP2 DNA binding domain of transcription factors unique to plants, it specifies whorl 1 and 2 organ identity in A. thaliana [4,5]. During floral development, $A P 2$ is essential for the determination of the identity of sepals and petals. In the weak ap2 mutants, leaf-like organs replace sepals, and petals exhibit antheroid characteristics, and in the strong ap2 mutants, carpels are formed in the outer whorl of the flower, petals are absent, and the number of stamens is reduced [6-9]. It is especially valuable for oilseed rape (B. napus) breeding that $A P 2$ is also involved in ovule and seed development $[5,10]$, regulation of seed size $[11,12]$, and the maintenance of the stem cell niche of the shoot meristem [13]. It has been shown that $A P 2$ and its closest homologs are the targets of miR172, which down regulates these target genes by a translational inhibition mechanism rather than by RNA cleavage [14].

$A P 2$ homologs that share similarities in gene structure and function with $A P 2$ have been isolated from numerous species. The putative Petunia hybrida ortholog, $A P 2 a$, is capable of complementing ap2 mutants of Arabidopsis. In Petunia, however, knockout mutations of $A P 2 a$ did not affect floral organ development, suggesting that $A P 2$ function is redundant in this species [15]. Similarly, two close homologs, LIP1 (LIPLESS1) and LIP2, have 
been identified in Antirrhinum majus, both of which need to be inactivated to get an ap2-like phenotype [16]. Recently, the closest tomato homolog of $A P 2, A P 2 a$, plays a critical role in fruit ripening via regulation of ethylene biosynthesis and signaling [17].

RNA interference (RNAi) is a mechanism of RNA based posttranscriptional gene silencing (PTGS) in eukaryotic cells and has been routinely applied to characterize the gene function and to engineer the novel phenotypes in model plants as well as in cultivated plants. With the recent discovery of gene expression control via small interfering RNA (siRNA) and micro RNA (miRNA) molecules, biologists are exploring genes and development from a new perspective [18]. Understanding of this ubiquitous phenomenon has revealed that RNA interference (RNAi) was a powerful tool to manipulate gene expression and to analyze gene function [19,20]. Gene constructs encoding direct inverted repeats of the target gene with an intervening functional intron (commonly referred to as intron interrupted hairpin RNA, ihp-RNA) have been shown to induce PTGS with almost $100 \%$ efficiency when directed against viruses or endogenous genes [21$25]$, and are more efficient compared to either antisense or cosuppression [26,27].

For B. napus, no ap2-like mutants have been identified so far. In this study, we reported the isolation, identification and characterization of $B$. napus AP2 (BnAP2) gene. To determine whether $B n A P 2$ gene represented the $A$. thaliana $A P 2$ (AtAP2) ortholog, we compared BnAP2 with the complete set of AP2-domain genes in Arabidopsis using the MEGA5.0 software package, analyzed the expression patterns of BnAP2 in different organs of B. napus by RTPCR. We had further demonstrated the functional conservation of the BnAP2 by complementing the ap2-11 mutant of Arabidopsis [12]. To study the transcriptional activation of $B n A P 2$, we had performed transactivation assays in yeast. Using fusions to the GAL4 DNA binding domain, we showed that the N-terminal of BnAP2 was required and sufficient for transcriptional activation in yeast. Finally, we studied the function of BnAP2 using the transgenic approach that involved targeted RNA interference repression induced by ihp-RNA in B. napus, floral various phenotype defectives and reduced female fertility were observed in BnAP2-RNAi lines, loss of the function of BnAP2 gene also resulted in delayed abscission and senescence of sepals, in the strong BnAP2-RNAi lines, seeds showed defects in shape, structure and development and larger size. All the results strongly support the conclusions that BnAP2 gene is the ortholog of AtAP2, and plays a critical role in flower identity and seed development of $B$. napus.

\section{Results}

\section{Isolation and sequence analysis of $B n A P 2$}

Total RNA was extracted from the flower buds of $B$. napus cultivar Zhongshuang 9 and SMART cDNA was synthesized using the purified mRNA as a template. According to the known homologous sequence of $A$. thaliana, the specific primers $\mathrm{P} 1$ and $\mathrm{P} 2$ (Table S1) were designed and the coding sequence (CDS, 1, 299 bp) of BnAP2 cDNA was obtained from SMART cDNA. The $B n A P 2$ sequence was submitted to GenBank under the accession number HQ637468.1.

The BnAP2 cDNA encoded a protein of 432 amino acid residues (Fig. 1). Similarity searched using tBlastn revealed that the AtAP2 protein is the most homologous entry in the GenBank database. BnAP2 showed $86 \%$ overall amino acid identity with AtAP2 and 80\% identity with Brassica rapa AP2 (BrAP2). Only fulllength sequences with at least $53 \%$ amino acid identity were used for further sequence comparison by CLUSTAL X. All possessed high levels of sequence similarity in the double AP2 domain regions (Fig. 1). In addition, the similarity of selected sequences were not limited to the AP2 domains but extended through the reading frame of these genes. A serine-rich putative transcription activation domain (amino acids 16 to 46) [5] and the linker that connected AP2 domains, are conserved, and a putative nuclear localization signal (amino acids 123 to 132) [5] is completely conserved at the amino acid level (Fig. 1). Interestingly, although the relationship of B. napus and B. rapa is closer than the other species selected, the levels of sequence similarity of the AP2 domains and the linker are lower (Fig. 1). Nine amino acid substitutions and sixteen amino acids deletions exist in the AP2 domains between BnAP2 and BrAP2 genes compared with other AP2-(like) genes, seven amino acids substitutions and 16 deletions of 25 full linker sequences of the predicted occurred (Fig. 1), while the amino acids mentioned above are conserved in the other AP2-(like) genes. Since B. napus is a allotetraploid species resulting from a cross between $B$. rapa and $B$. oleracea [28], these data suggest that the cloned $B n A P 2$ is the $B$. oleracea copy of $A P 2$.

To further evaluate the homology between BnAP2 and AP2domaingene family in Arabidopsis, we compared BnAP2 with the complete set of AP2-domain in Arabidopsis using the MEGA5.0 software package. And the result indicated that At4g36920, one member of AP2 /EREBP gene family in Arabidopsis, is one homolog of BnAP2 in B.napus (Fig. 2). In addition, the miR172 target site is also present in $B n A P 2$ gene through the sequence comparison between BnAP2 and AtAP2. The putative miRNA172 binding site is located within the coding region of $B n A P 2$ gene but is outside of the conserved $A P 2$ domains. Nucleotides in BnAP2 RNA that can base-pair with miRNA172 (with G:U pairing allowed) are 1178 CUGGAGGAUGAUGAGGAUUCU1198.

\section{The copy number and expression pattern of $B n A P 2$}

The copy number of the BnAP2 gene in the B. napus genome was estimated by DNA gel blot analysis. B. napus genomic DNA was digested with various restriction endonucleases, fractionated, transferred, and hybridized with the CDS of BnAP2 cDNA as a probe. As shown in Figure 3A, a small number of bands were observed for each DNA digest, indicating that there may be a few copies of BnAP2 gene in the genome of $B$. napus.

To monitor the expression pattern of the BnAP2 gene, we isolated total RNAs from different tissues of B. napus plant, such as root, stem, leaf, bud, silique (including peel and seed together) and four types of floral organ-sepal, petal, stamen and carpel. By performing reverse transcription-polymerase chain reaction (RTPCR) analyses with BnAP2-specific primer pairs P1 and P3 (Table $\mathrm{S} 1), B n A P 2$ gene was clearly expressed at mRNA level in four types of floral organs and thus, functions during the development of all the floral organs (Fig. 3B). Since AtAP2 is regulated on the protein level by miR 172 in whorl 3 and 4, and the miR172 target site is also present in BnAP2 gene, Western blot analysis of the expression of BnAP2 protein was performed. And the result revealed that BnAP2 was expressed at the protein level in whorl 3 and 4 (Fig. 3C). At present, we could not obtain the antibody against BnAP2 protein, while BnAP2 showed $86 \%$ overall amino acid identity with AtAP2, and thus we used AtAP2 antibody, instead of BnAP2 antibody in Western blot. RT-PCR analyses with RNAs from root, stem, leaf, bud and silique indicated that BnAP2 gene was expressed in all these tissues, and detected weakly in root, stem and leaf, abundantly in bud and silique (Fig. 3D). These results showed that $B n A P 2$ gene was involved in more global function, in addition to flower identity. 
Petunia VitisAP2 LIPLESS 1 Malus

BnAP2

BrAP2

AtAP2

Petunia VitisAP2 LIPLESS 1

Malus

BnAP2

BrAP2

AtAP2

Petunia VitisAP2 LIPLESS 1

Malus

BnAP2

BrAP2

AtAP2

Petunia VitisAP2 LIPLESS 1

Malus

BnAP2

BrAP2

AtAP2

Petunia

VitisAP2

LIPLESS 1

Malus

BnAP2

BrAP2

AtAP2

Petunia VitisAP2 LIPLESS 1 Malus

BnAP2

BrAP2

AtAP2

Petunia VitisAP2 LIPLESS 1

Malus

BnAP2

BrAP2

AtAP2

Petunia VitisAP2 LIPLESSI

Malus

BnAP2

BrAP2

AtAP2

Petunia VitisAP2 LIPLESS 1 MalusAP2 BnAP2

BrAP2

AtAP2

Petunia

VitisAP2 LIPLESS 1 Malus

BnAP2

BrAP2

AtAP2
MWDLNDSPDQRREINIDESEEGCSS-HIELEPDDEKGKRVGSFS--TSSSSAIAID-EIS MWDLNDSPDQRR----DDESEGCSSQKTSVDSIDDKGKRVGSVSNENSSSSAVVIE-DGS MWDLNDSPDQRK-------------DEEPEGKWVGSVS--NSSSSAVVVE-DGS MWDLNDSPDQRPR---GEESEGCSSQKTSADGDEEKRKRVGSVS--NSSSSAVVIEEDGS MWDLNDAPHQTVR--QEESEEFCYS--------SPGKRVGSFS--NSSSSAVVIE-DGS MWDLNDSPHQTLV--EEESEELCYS---------SPGKRVGSFS--NSSSSAVVIE-DGS MWDLNDAPHQTQR--EEESEEFCYS---------SPSKRVGSFS--NSSSSAVVIE-DGS

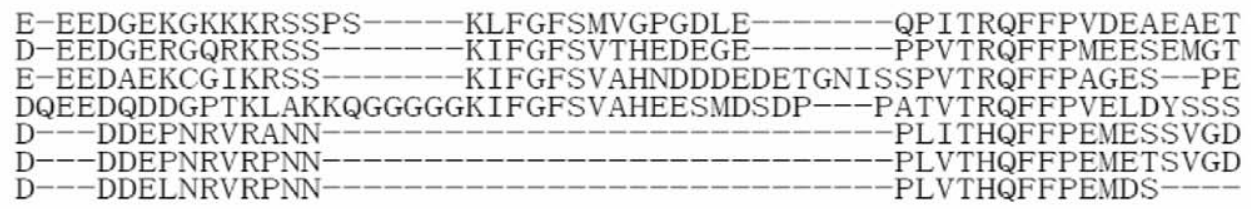

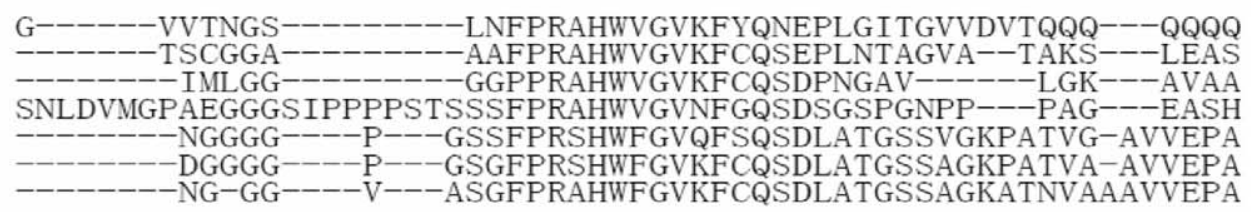

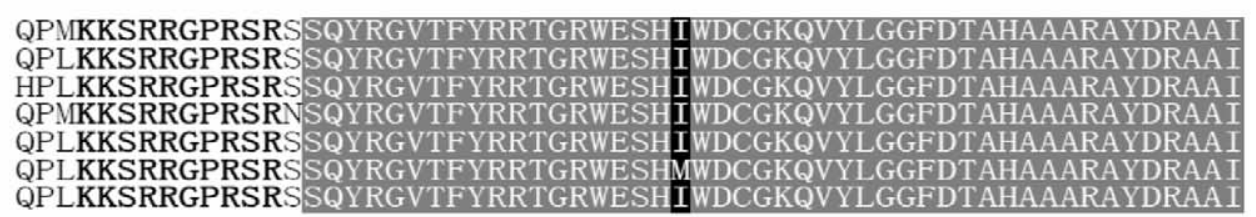
QPLKKSRRGPRSRSSQYRGVTFYRRTGRWESH IWDCGKQVYLGGFDTAHAAARAYDRAA I
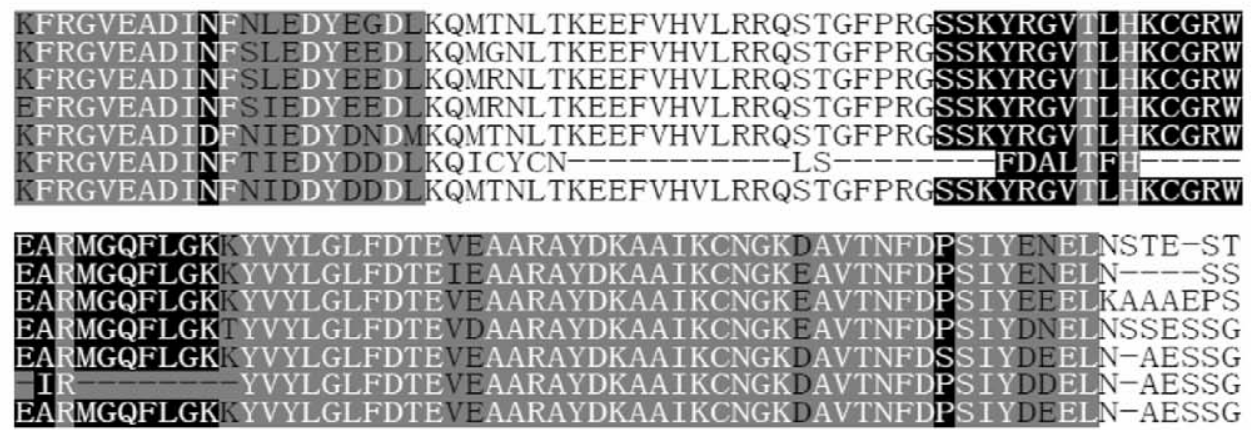

DS--GADHNLDLSLGGSSSKKNNREFGDNR--------GQNPSSMQFDVDWRHNGLRP-GN--AADHNLDLSLGGSASKQNNLELGDDSQVV---TMDQHSVGMSFEADWRSRGFRP-NK--AADHDLDLSLGNSASKSSGQRPGFVD--------QPPSSSMTFEVDWRRHGLKP-VI--AADHNLDLSLGSTNSKKNNQALGNDHHSQNVAMEHQHSVSMQLDANWRSQGLRPKL NP-IQHDHNLDLSLGNS---VNSK----------HNGQDMRLKMNQQNP-IQHDHNLDLSLGNS---VNSK-------------- QKGQDMRLKMNQQ NPTTPQDHNLDLSLGNS---ANSK---------------HKSQDMRLRMNQQQQ------

--EKQTAPVDMD-ARRRDNGYNESETLQLLSKTHLHSPVSLKHNNSHQLQRFGQYMRPGE --KQEACKSDGD-ALRR-NGYNEMETMQLLSHTHLQSPAALKPG---EMYRYGQFRRAGE --ENHMTSTDIDNPRRRDNGYSETETLQLLSQTHLNSPGMLKAND--ERHRFGQLGKTHE NIQRDRSRDD ID-AQRR-DGYSESEAMQLLLRTNLQSQAPAEVH---KYGQFNRRLTAGD
$---D^{-}$

SHMIQMFPPQFGSSNY-QIQFPSGSNGGRIG---ATNVGDLSLSSSNASSQWQSNLPPQTQMLHILPPQLSSPNY-QIQFPSSSNGGRI----AVNGGDLSLATN--HQQWQS-GPPQPHMIQMFNTPFTSQNYHQIYHNFPAAGASVSGSRNVNGGEFNNYVARNEQQWQMN-HHQIQMSHNFPPNFNSPNYHHIQFPSSSEGGGR------IGSDLSLSTSDHQQQWQSATPTSN -GMVNYIP----DSVH---QFPGSSNIHG------- GGGFSLFPVTENHQFEGRTTANQ -GMVNHIP----NSNL---QFPGSSNIGG--------GGGFSLFPVAENHRFDGRTTTNQ -GMLNHTP----NSNH---QFPGSSNIGS------- GGGFSLFPAAENHRFDGRASTNQ

IFAAAAASSGFSQQ-----IVRP----QNWSS-ENGFHHF-LMRPS LFATAAASSGFPPQ-----MIRPN---QQWPQ-KNGFHS--LIRPS LFASAAASSGFPHAPPLLSSSRP----RDWPLQKNGFHSSYNIRPS LFATAAASSGFPPQ-----LRPLPTQNSWLQ-KNGFHT-LARRVLANAAASSGFSPHNHHQIFNSTPTSHQNWLQ-TNGFQPP-LMRPS VLANAAASSGFSPHHHNQIFNSTSTSHQNWLQ-TNGFQPS-LMRPS VLTNAAASSGFSPHHHNQIFNSTSTPHQNWLQ-TNGFQPP-LMRPS

Figure 1. Analysis of the deduced amino acid sequences of BnAP2. Comparison of the deduced amino acid sequences of Brassica napus AP2like transcriptional factor gene (BnAP2) with other AP2-like genes through CLUSTAL X (1.8) multiple sequence alignment software. Comparison of the overall amino acid sequences, the AP2 domains (shaded), linkers, and putative nuclear localization signals (in boldface) of BnAP2 (GenBank accession 
number ADU04499.1), Arabidopsis thaliana APETALA 2 (AtAP2) (AEE86718.1), B. rapa AP2-like transcriptional factor (BrAP2) (AAX47049.1), Vitis vinifera transcription factor APETALA2 (VitisAP2) (ACO52508.1), Malus $\mathrm{x}$ domestica transcription factor AHAP2 (Malus AP2) (AAL57045.2), Petunia $\mathrm{x}$ hybrida PHAP2A protein (Petunia AP2) (AF132001), and Antirrhinum majus LIPLESS1 (AAO52747.1). Amino acids in the AP2 domains, which are conserved in all mentioned sequences, are in white on a shaded background. The different amino acids in the AP2 domains of BnAP2 and BrAP2 are white on black. Gaps are indicated by dashes.

doi:10.1371/journal.pone.0033890.g001

BnAP2 complements the ap2-11 mutant of Arabidopsis

To further identify BnAP2 as the functional ortholog of $A t A P 2$, we decided to express BnAP2 in the ap2-11 mutant of Arabidopsis to determine whether this might result in complementation. The ap211 mutant resulted from an 11-bp deletion in the AP2 gene (bases +724 to +734 relative to the transcription start site, GenBank accession no. U12546), this region encodes the first AP2 domain of the protein. The strong ap2-11 mutant had floral defects similar to those of an ap2 mutant [7,9]. Sepals were transformed into carpeloid organs, petals failed to develop in the second whorl, and stamen number was reduced. The binary vector pBI121-35S BnAP2 was used to transform the ap2-11 mutant (see Methods). All the five independent transformants generated phenotypically wildtype flowers (four sepals, four petals, six stamens) (Fig. 4). Together

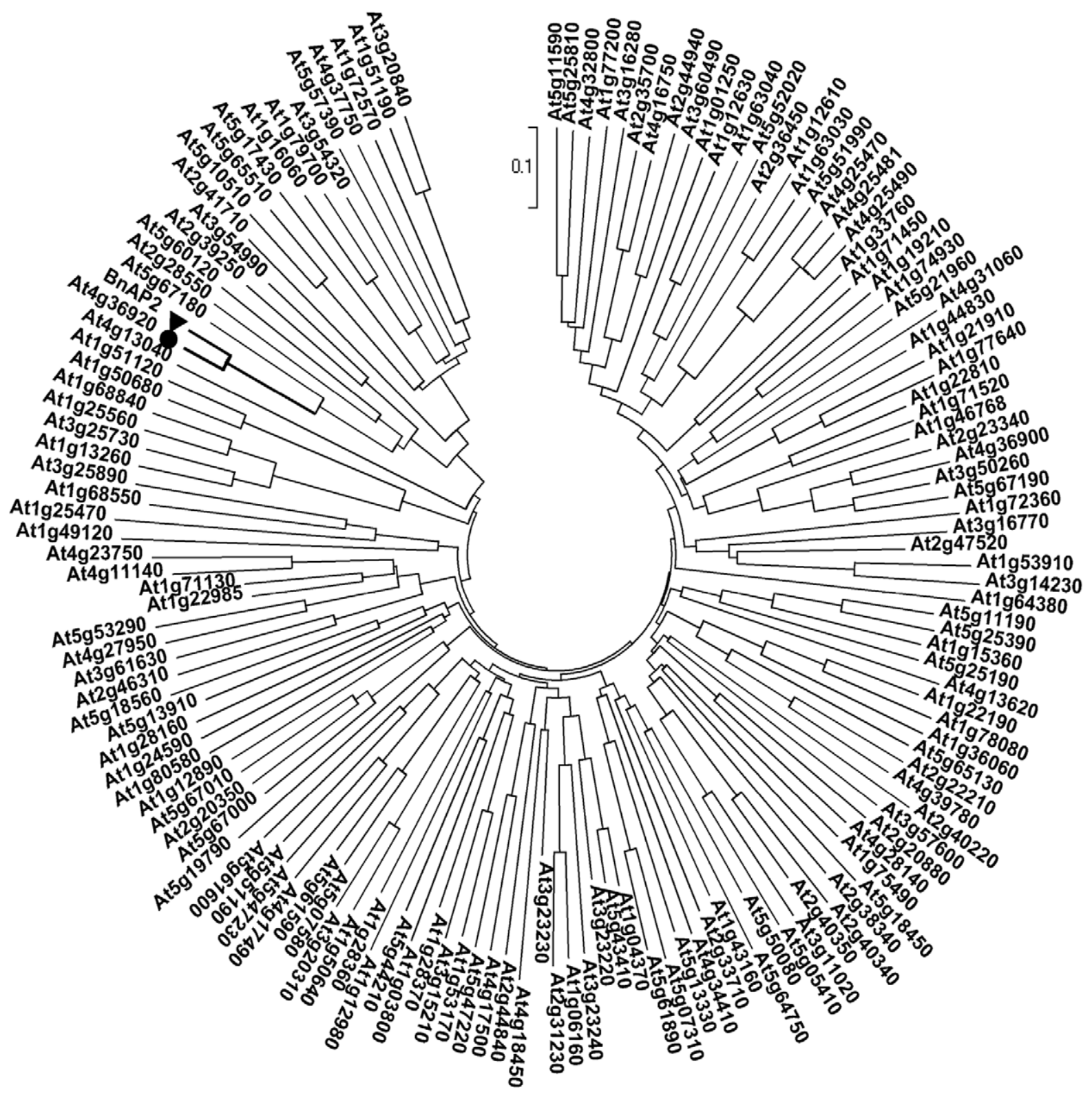

Figure 2. Phylogenetic analysis of BnAP2 and the complete set of AP2-domain in Arabidopsis. Phylogenetic relationship was inferred using the Neighbor-Joining method and evolutionary distances were computed using the p-distance method. Assessment of each node confidence was done by means of 1,000 bootstrap replicates. BnAP2 were denoted with black filled circle and At4g36920, the homolog of BnAP2 in A. thaliana with black filled triangle.

doi:10.1371/journal.pone.0033890.g002 
A

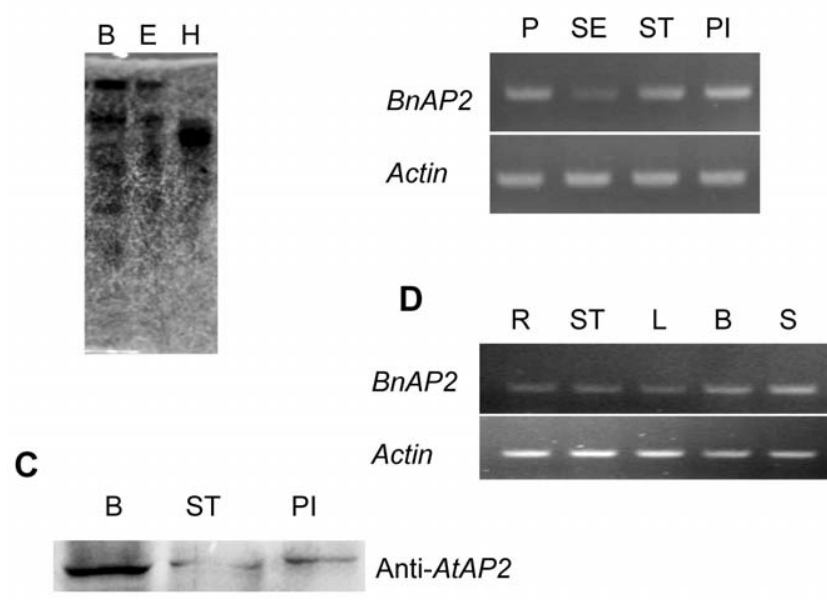

Figure 3. Genomic DNA gel blot analysis and organ-specific expression of BnAP2 in Brassica napus. A, DNA gel blot analysis of the BnAP2 gene. Genomic DNA (30 ug) was digested with BamHI (B), EcoRI (E), and Hindlll $(\mathrm{H})$, and gel separated. The DNA gel blots were hybridized with the full length BnAP2 CDNA. B, RT-PCR of RNA isolated from B. napus (Zhongshuang 6) petal (P), sepal (SE), stamen (ST), and pistil (PI) using gene-specific primers for $B n A P 2$. The loading control was Actin. C, Western blot analysis of the expression of BnAP2 protein in flower buds (B), stamen (ST), pistil (PI) in Brassica napus with the antibody against AtAP2 proein. D, RT-PCR of RNA isolated from $B$. napus (Zhongshuang 6) root (R), stem (ST), leaf (L), bud (B) and silique (S) using gene-specific primers for BnAP2. The loading control was Actin. doi:10.1371/journal.pone.0033890.g003

with the sequence and expression data, the complementation data proved that BnAP2 encodes the AtAP2 ortholog in B. napus.

\section{The BnAP2 protein has transcriptional activation activity in yeast}

As shown in Figure 1, by comparison with other $A P 2$-(like) genes, $B n A P 2$ has a serine-rich domain that might act as putative transcription activation domain (amino acids 16 to 46) [5]. To investigate the functional role of this region of $B n A P 2$, we fused the CDS for BnAP2 and its mutants to the GAL4 DNA binding domain expression vector (Fig. 5A) and examined the behavior of each construct as a potential transcriptional activator in yeast (Fig. 5, B and $\mathrm{C}$ ). In the absence of the GAL4 activation domain, the wildtype BnAP2 protein fused to the GAL4 DNA binding domain activated the transcription of lac $Z$ reporter gene. This result indicated that the BnAP2 protein was capable of functioning as a transcriptional activator in yeast. To identify a minimal transcriptional activation domain of BnAP2, various deletion mutants of BnAP2 also were tested in the same manner. The BnAP2 $\Delta \mathrm{C} 1$, BnAP2 $\Delta \mathrm{C} 2, \mathrm{BnAP} 2 \Delta \mathrm{C} 3, \mathrm{BnAP} 2 \Delta \mathrm{C} 4$ and BnAP2 $\Delta \mathrm{C} 5$ mutants, which lacked 59, 119, 179, 232, 332 C-terminal amino acids, respectively, showed almost complete $\beta$-galactosidase activity (Fig. 5, $\mathrm{B}$ and $\mathrm{C}$ ), while BnAP2 $\Delta \mathrm{N}$ mutant which lacked $100 \mathrm{~N}$-terminal amino acids, demonstrated absence of complete $\beta$-galactosidase activity (Fig. 5, B and C), indicating that the N-terminal 100 amino acids of BnAP2 play an important role in supporting the ability of $\mathrm{BnAP2}$ as a potential transcriptional activator.

\section{Generation of the stably inherited BnAP2-RNAi transgenic B. napus plants}

We constructed an RNAi vector targeting a $5^{\prime}$ terminal 400-bp cDNA fragment of BnAP2. The resulting construct, designated
BnAP2-RNAi, contained the sequence encoding N-terminal transcriptional activation region in an inverted repeat orientation under the transcriptional control of the cauliflower mosaic virus 35S promoter (Fig. 6A). Transformation was performed as the method reported by De Block et al. [29]. Kanamycin-resistant regenerated plantlets that were phenotypically identical to untransformed plants, rooted well in selective medium, were firstly subjected to PCR-based screening with $\mathcal{N} P T I I$ gene specific primers P19 and P20 (Table S1). A total of 6 independent BnAP2RNAi transgenic lines were obtained (Fig. 6B). The transgenic nature for each of them was further confirmed by Southern-blot analysis (Fig. 6C). The results indicated that the transgenic lines BnAP2-RNAi-3, BnAP2-RNAi-4, BnAP2-RNAi-18 and BnAP2RNAi-26 had a single copy of the transgene, and the transgenic lines BnAP2-RNAi-1 and BnAP2-RNAi-2 had two copies of the transgene. In the second generation, the lines BnAP2-RNAi-3, BnAP2-RNAi-4, BnAP2-RNAi-18 and BnAP2-RNAi-26 segregated in a 3:1 ratio for the transgene as determined by PCR detection. For the lines BnAP2-RNAi-1 and BnAP2-RNAi-2, the ratio was 15:1. From the fourth generation, these lines were no longer segregating for the transgene and thus were considered homozygous. BnAP2 transcripts could not completely be detected in homozygous transgenic lines BnAP2-RNAi-1, BnAP2-RNAi-18 and $B n A P 2-R N A i-26$ by RT-PCR analyses with $B n A P 2$-specific primer pairs, while $B n A P 2$ gene expression was not decreased in homozygous transgenic lines BnAP2-RNAi-2, BnAP2-RNAi-3 and BnAP2-RNAi-4 (Fig. 6D).

\section{Floral patterning defects in BnAP2-RNAi lines}

Figure 7 shows representative defective phenotypes of flowers in homozygous BnAP2-RNAi lines. Out of six analyzed transformants, one BnAP2-RNAi line, BnAP2-RNAi-18, shows a milder phenotype (Fig. 7A), and two BnAP2-RNAi lines, BnAP2-RNAi-1 and BnAP2-RNAi-26, exhibit severe alterations in flower identity and development (Fig. 7, B and C), and the other three BnAP2RNAi lines, BnAP2-RNAi-2, BnAP2-RNAi-3 and BnAP2-RNAi-4, show no obvious floral patterning defects (data not shown).

As for strong floral defects, the sepals in the first whorl were greatly increased in size, both in length and in width, showing distinct leaf-like characteristics, such as a thinner blade in which venation could be easily observed (Fig. 7D). In addition, the number of sepals reduced, some sepals were fused along the margins, curled at the tip and then transformed into carpeloid organs carrying multiple ovules along the margin, in the late arising or distal flowers along the primary inflorescence (Fig. 7E). The second whorl petals also exhibited dramatic defects. The petals were either absent or reduced in number from four in wild type to between one and three organs. Frequently the petals within a single flower were variable in shape, which formed an aberrant bell-like structure (Fig. 7F). The visible phenotypic defects were in the third whorl of the flower where some stamens were frequently converted to filamentous structures (average 1.59 filaments/flower in BnAP2-RNAi-1 and average 1.68 filaments/flower in BnAP2RNAi-26, Table 1) that resembled stamen filaments, but had no anther-like structure at the distal end of the filament (Fig. 7G). In most cases, the structures of stamens were morphologically normal, but the number reduced. The average number of organs that developed in third whorl positions was 2.34 in the line BnAP2RNAi- 1 and 2.57 in the line BnAP2-RNAi-26 (wild-type average 6 organs), which indicates that there was a frequent failure of organ development in the third whorl of strong BnAP2-RNAi lines (Table 1). Most of the fourth whorl carpel were morphologically abnormal, the size was somewhat longer (Fig. $7 \mathrm{H}$ ), and 


\section{A}

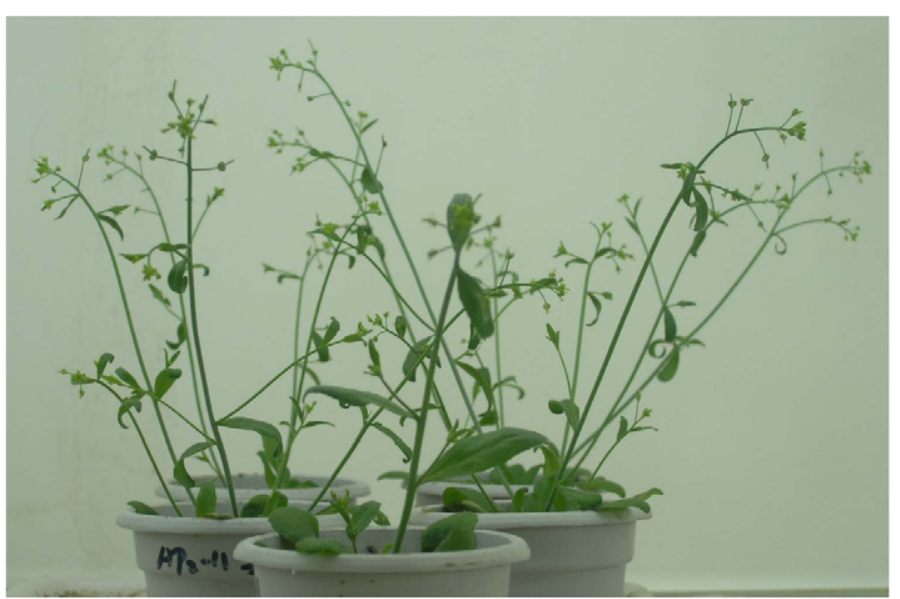

B

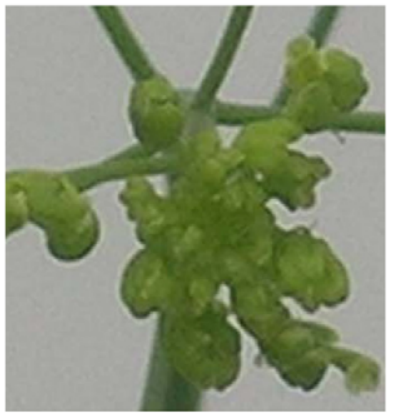

E

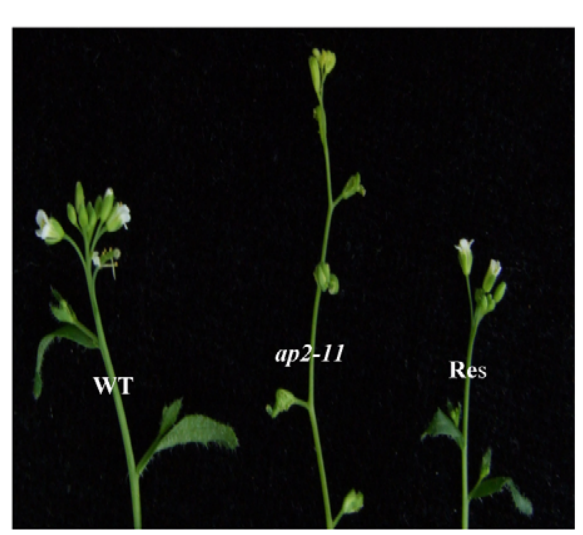

C

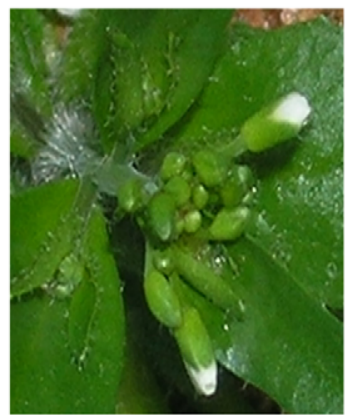

D

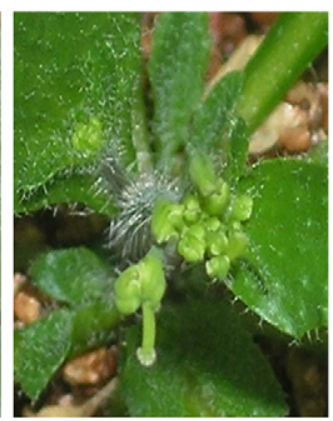

$\mathbf{F}$

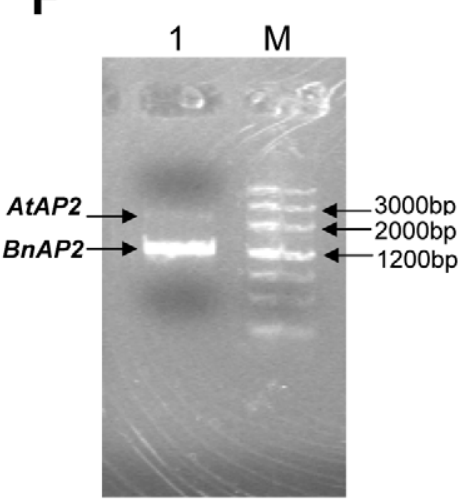

Figure 4. Complementation of the Arabidopsis ap2-11 mutant by BnAP2. Arabidopsis ap2-11 flower has abnormal phenotype. A, Arabidopsis ap2-11 mutant plants. B, The inflorescence of Arabidopsis ap2-11 mutant. C, Flower phenotypes of restoration plants of Arabidopsis ap2-11 mutant transformed by 35S::BnAP2. D, Flower phenotypes of Arabidopsis ap2-11 mutant. E, The inflorescences of wild type (WT), ap2-11 mutant (ap2-11) and phenotypic restoration (Re) plants. F, PCR analysis of the pBI121-BnAP2 construct with primers P6 and P7, using Arabidopsis transgenic plant genomic DNA as the template. Lane 1: PCR amplification bands for AtAP2 (2860 bp) and BnAP2 (1299 bp); Lane M: DNA marker III. doi:10.1371/journal.pone.0033890.g004

occasionally misshapen and bent carpels were observed in the late arising or distal flowers (Fig. 7I).

In the weak line BnAP2-RNAi-18, floral defects only focused on the whorl 2 and 3 floral organs, including that petals were aberrant in number and shape, stamens number was reduced. Table 1 summarized average floral organ number of per flower in above BnAP2-RNAi transgenic plants.

\section{Reduced fertility in BnAP2-RNAi transgenic plants}

BnAP2 RNAi also induced other defects in reproductive development. Although flower number on the primary inflores- cences of mutant plants was similar to that of wild type, fertility was negatively affected by BnAP2-RNAi lines. For example, Table 2 shows that strong BnAP2-RNAi mutants produced fewer elongated siliques on the primary inflorescence compared with wild type. Pistils failed to elongate into siliques when ovules within the pistil had not been fertilized to a significant extent [30]. Consistent with this result, average seed number per silique was lower in RNAi lines as compared with that of wild type. The $B n A P 2-\mathrm{RNAi}$ mutants produced fewer seeds than wild type because of defects in fertility caused by reduction in BnAP2 activity. And the reduced fertility in mutants was most likely a 
A

pGBKT7

BnAP2

$\mathrm{BnAP2} \triangle \mathrm{C1}$

$\mathrm{BnAP2} \triangle \mathrm{C2}$

$\mathrm{BnAP2} \triangle \mathrm{C} 3$

$\mathrm{BnAP2} \triangle \mathrm{C} 4$

$\mathrm{BnAP2} \triangle \mathrm{C} 5$

$\operatorname{BnAP2} \triangle \mathbf{N}$

B
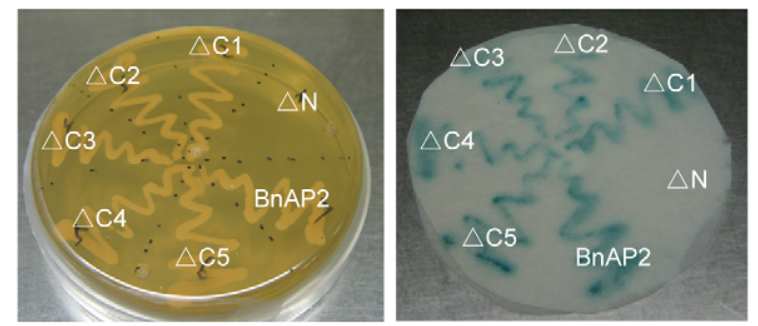

C

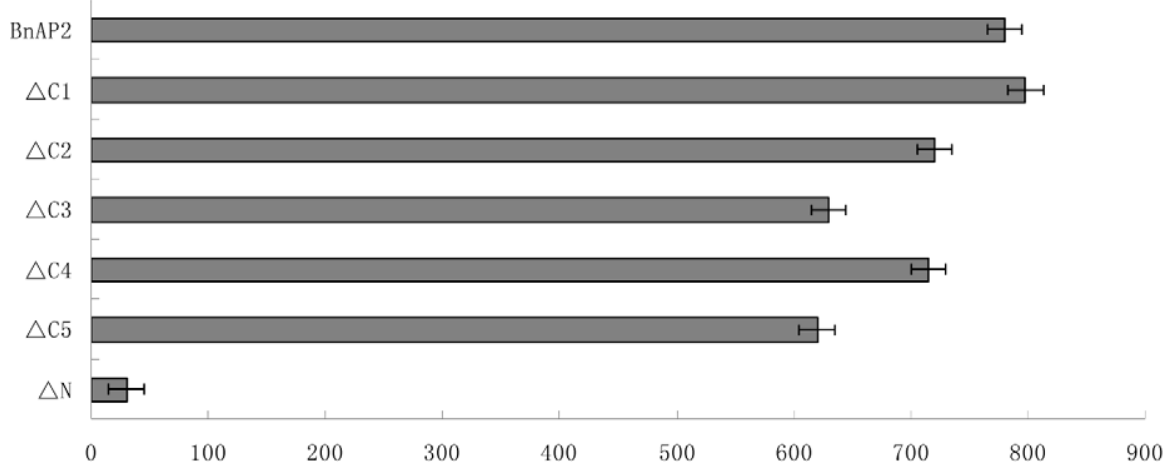

Figure 5. Transcriptional activation activity of $B n A P 2$ in yeast cells. The transcriptional activity of $B n A P 2$ was determined using a yeast assay system in which $B n A P 2$ was expressed in yeast strain $A H 109$ containing a lac $Z$ reporter gene. $A, B n A P 2$ constructs. Six constructs which were fused in frame to the GAL4 DNA binding domain (DB) expression vector were prepared containing various portions of BnAP2. B, Filter lift $\beta$-galactosidase assay was performed. $C$, The liquid $\beta$-galactosidase assay was performed using ONPG as a substrate. $\beta$-Galactosidase activity was then assayed and expressed in Miller units. For each construct, 4 different transformants were assayed. Bars represent standard error.

doi:10.1371/journal.pone.0033890.g005

consequence of defects in pollen or pistils. To determine pollen viability, fertility and quality, pollen test using I2-KI staining solution or aceto-carmine showed that there was no significant difference between results from the two staining methods. The average pollen viability rate of $B n A P 2-\mathrm{RNAi}$ line was $82.76 \%$ from I2-KI staining (Fig. 8A) and $81.58 \%$ from aceto-carmine staining (Fig. 8B). Pollen germination experiment in vitro showed that pollens from strong BnAP2-RNAi line had normal viability (Fig. 8C). Pollen germination on stigma was also confirmed in BnAP2-RNAi mutants by observing the germinating pollen tube on the stigmas $4 \mathrm{~h}$ after anthesis (Fig. 8D), Moreover, germinating pollen tubes could enter into ovules (Fig. 8E). In reciprocal crosses experiment, male fertility was further assessed using BnAP2-RNAi mutant as the pollinator to cross to Zhongshuang 6 , and the average number of seeds each silique produced by this cross was normal; female fertility was assessed using BnAP2-RNAi mutants as female parent to cross with Zhongshuang 6, the average number seeds each silique produced by this cross was similar to BnAP2-RNAi mutants (Table 3). These results showed that knockdown of the expression of BnAP2 gene had no effect on pollen viability, fertility and quality, and aberrant pistils induced reduced seed set rate in BnAP2-RNAi mutants.

\section{Delayed sepal abscission and senescence induced in strong BnAP2-RNAi lines}

After anthesis occurs in wild-type plants, the sepals, petals, and stamens normally abscise in a short period. As shown in Figure 9A, the floral organs were detached from the siliques in about 3 days after pollination in wild-type B. napus plants. In contrast, in strong BnAP2-RNAi lines, although the petals and stamens normally 
A

\section{Notl EcoRI Kpnl BamHI Xbal Notl}

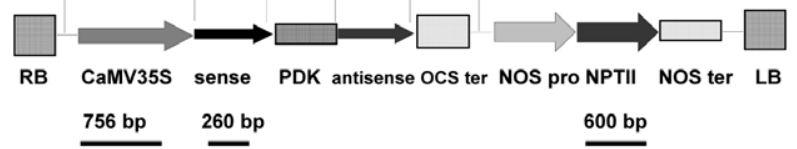

B

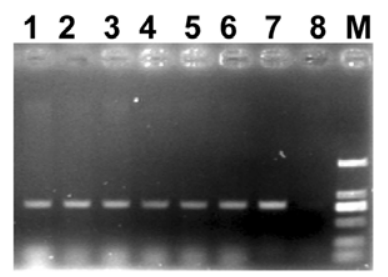

D $\begin{array}{lllllll}1 & 2 & 3 & 4 & 5 & 6 & 7\end{array}$

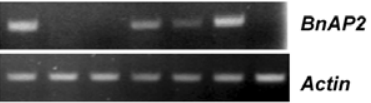

C

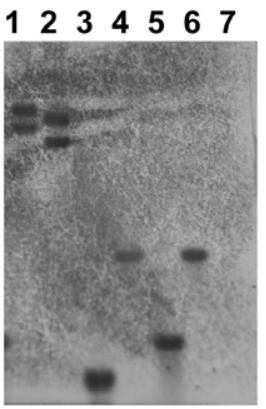

Figure 6. Transformation of $B$. napus cultivar Zhongshuang 6 with intron-spliced hairpin RNA (ihpRNA) as RNAi construct that targets $B n A P 2$ gene. $A$, Schematic diagram of T-DNA of the binary vector pBnAP2-RNAi. RB, right border; CaMV 35S, CaMV 35S promoter; Anti-sense, fragment in anti-sense orientation; PDK, PDK intron; sense, fragment in sense orientation; OCS ter, OCS terminator; NOS pro, NOS promoter; NPT II, neomycin phosphotransferase gene; NOS ter, NOS terminator; LB, left border. The sites of a 756-bp probe used for Southern blot, a 600-bp fragment used for PCR template and a 260-bp used for RT-PCR were indicated. B, PCR analysis of the RNAi construct transgenic plants using genomic DNA as the template. Lane 1, positive control ( $\mathrm{pBnAP2-RNAi);} \mathrm{lane} \mathrm{8,} \mathrm{untransformed} \mathrm{Zhongshuang}$ 6 (CK1); lanes 2-7, the tested transgenic plants BnAP2-RNAi-1, BnAP2RNAi-2, BnAP2-RNAi-3, BnAP2-RNAi-4, BnAP2-RNAi-18 and BnAP2-RNAi26, respectively; M, DL 2000 marker. C, Southern-blot analysis of the BnAP2-RNAi transgenic plants. Lane M, DNA marker (unit, bp); lane 7, untransformed Zhongshuang 6 (CK1); lanes 1-6, the tested transgenic plants BnAP2-RNAi-1, BnAP2-RNAi-2, BnAP2-RNAi-3, BnAP2-RNAi-4, BnAP2-RNAi-18 and BnAP2-RNAi-26, respectively. Genomic DNA from all transgenic and CK1 plants was digested by Kpnl. D, RT-PCR analysis of the BnAP2 gene in the BnAP2-RNAi transgenic plants. lane 1, untransformed Zhongshuang 6 (CK1); lanes 2-7, the tested transgenic plants BnAP2-RNAi-26, BnAP2-RNAi-18, BnAP2-RNAi-4, BnAP2-RNAi-3, $B \cap A P 2-R N A i-2$ and $B \cap A P 2-R N A i-1$, respectively.

doi:10.1371/journal.pone.0033890.g006

abscised following pollination, the sepals remained attached closely at almost all positions of the inflorescence (Fig. 9A), even during later silique development (Fig. 9B).

Senescence usually occurs synchronously with the abscission process in wild-type plants. Therefore, in some mutants with abscission-delayed genetic modifications, such as the Arabidopsis etr1-1 mutant, the senescence process is also slowed down [31]. We examined the timing of sepal yellowing and the timing of floral organ withering in the wild type and the BnAP2-RNAi lines. Just like etr1-1, the sepals of the BnAP2-RNAi lines showed a blocked progression of senescence compared with that of the wild type that showed yellowing on second day after pollination and withering in 3 days after pollination (Fig. 9, C and D). In contrast, sepals of BnAP2-RNAi lines kept green following pollination, even with the whole progress of silique development (Fig. 9B).

The strong BnAP2-RNAi plants are sensitive to ethylene

Abscission processes have been divided into ethylene-dependent and ethylene-independent types [31]. To test the ethylene sensitivity of strong BnAP2-RNAi plants, a typical "triple-
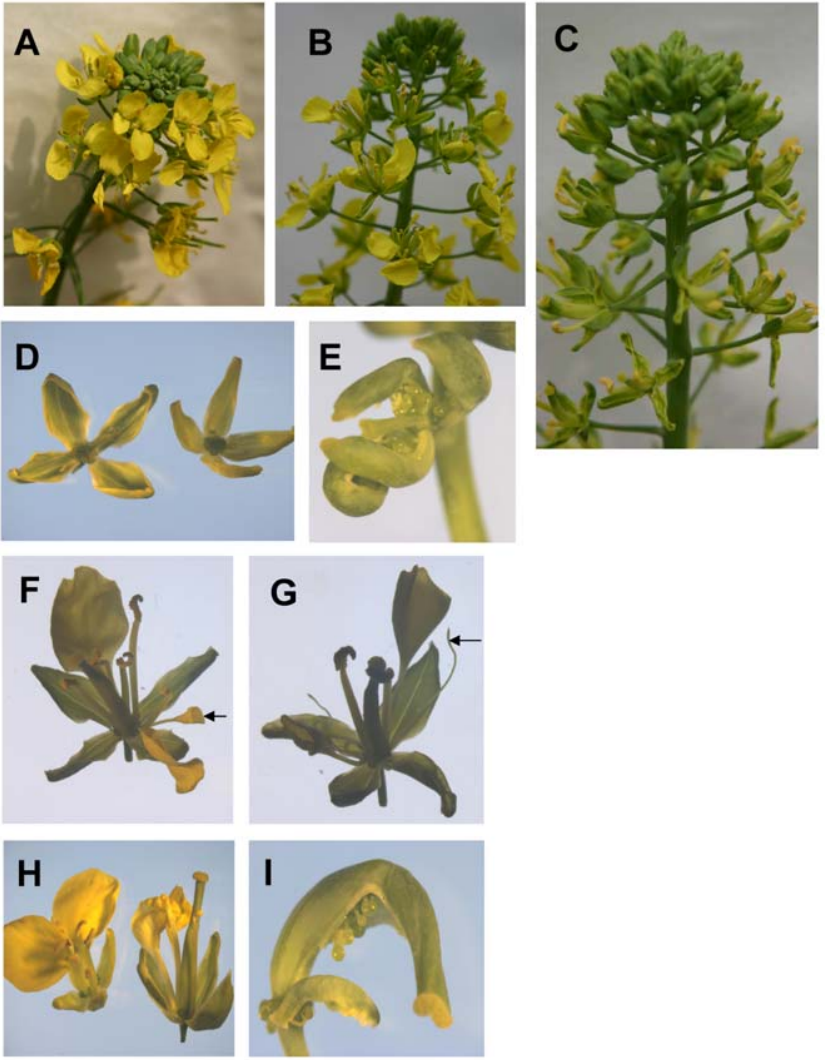

Figure 7. Changes in the number of floral organs and floral identity in the BnAP2-RNAi transgenic plants. A, Weakly phenotypic BnAP2-RNAi-18 transgenic plant: only involved in reduced numbers of petals in whorl 2 and stamens in whorl 3. B and C, Loss of floral determinacy in severely phenotypic BnAP2-RNAi-26 and BnAP2RNAi-1 transgenic plants. D-I, Loss of floral determinacy in severe BnAP2-RNAi transgenic plants. D, Sepals were greatly increased in size, both in length and in width, showing distinct leaf-like characteristics, such as a thinner blade in which venation could be easily observed. E, Sepals were fused along the margins, curled at the tip and then transformed into carpeloid organs carrying multiple ovules along the margin. F, Petals formed a aberrant bell-like structure (arrow). G, Stamens converted to filamentous structures (arrow). $\mathrm{H}$, The size of carpel in BnAP2-RNAi transgenic plant was somewhat longer than that in wild type plant (right, wild type; left, BnAP2-RNAi transgenic plant). I, Misshapen and bent carpel.

doi:10.1371/journal.pone.0033890.g007

response" assay [32] was used to determine whether strong BnAP2-RNAi plants have normal ethylene perception and response. Seeds germinated vertically in the dark on growth medium supplemented with $5 \mathrm{mM} 1$-aminocyclopropane-1-carboxylic acid (ACG), which is the natural precursor of ethylene. The strong BnAP2-RNAi plants displayed similar triple-response morphological changes compared with the wild-type plants, including the inhibition of hypocotyl growth and root elongation, radical swelling of the hypocotyls, and exaggeration of the curvature of the apical hook (Fig. 10). Therefore, the strong BnAP2-RNAi seedlings did not show any deficiency in the perception and response to ethylene.

\section{BnAP2 is involved in seed development}

Except floral defects, mild BnAP2-RNAi lines did not visibly exhibit other defects under standard growth conditions. However, we found that the seeds of self-pollinated strong BnAP2-RNAi lines were structurally and developmentally defective by comparing 
Table 1. Average flower organs No. of per flower in BnAP2-RNAi transgenic plants.

\begin{tabular}{|c|c|c|c|c|c|c|}
\hline \multirow[b]{2}{*}{ Genotype } & \multicolumn{2}{|c|}{ Average No. of Whorl 1} & \multicolumn{2}{|c|}{ Average No. of Whorl 2} & \multicolumn{2}{|c|}{ Average No. of Whorl 3} \\
\hline & Sepals & Carpeloid Sepals & Petals & Bell-like Petals & Stamens & Filament \\
\hline BnAP2-RNAi-1 & 2.92 & 0.85 & 2.19 & 1.21 & 2.34 & 1.59 \\
\hline BnAP2-RNAi-26 & 2.64 & 1.07 & 2.87 & 1.54 & 2.57 & 1.68 \\
\hline BnAP2-RNAi-18 & 4 & 0 & 3.12 & 0.87 & 6 & 0 \\
\hline Wild type & 4 & 0 & 4 & 0 & 6 & 0 \\
\hline
\end{tabular}

wild-type and mutant seed. As shown in Figure 11, seeds of strong BnAP2-RNAi lines had defects in shape, size, structure and development. Compared with the wild type, the fully mature seeds from BnAP2-RNAi-1 and BnAP2-RNAi-26 lines had a distorted shape, exhibiting strong indentations resulting in less round seed (Fig. 11A). The surface of the fully mature BnAP2-RNAi seed was bumpy, and frequently, radicels drilled out from mature seeds (Fig. 11B), causing dry seeds to fail in germination (data not shown). Additionally, mature seeds of BnAP2-RNAi-1 line were larger in size than those of wild type (Fig. 11A). However, the abortive seeds in strong BnAP2-RNAi lines were especially interesting, which were abnormal in shape and empty (Fig. 11C). The embryo of abortive seeds was also abnormal in morphology (Fig. 11D). We compared the morphological and developmental changes between abortive and wild-type seeds. Figure $11 \mathrm{E}$ shows that there were no obvious changes in total seed protein content in
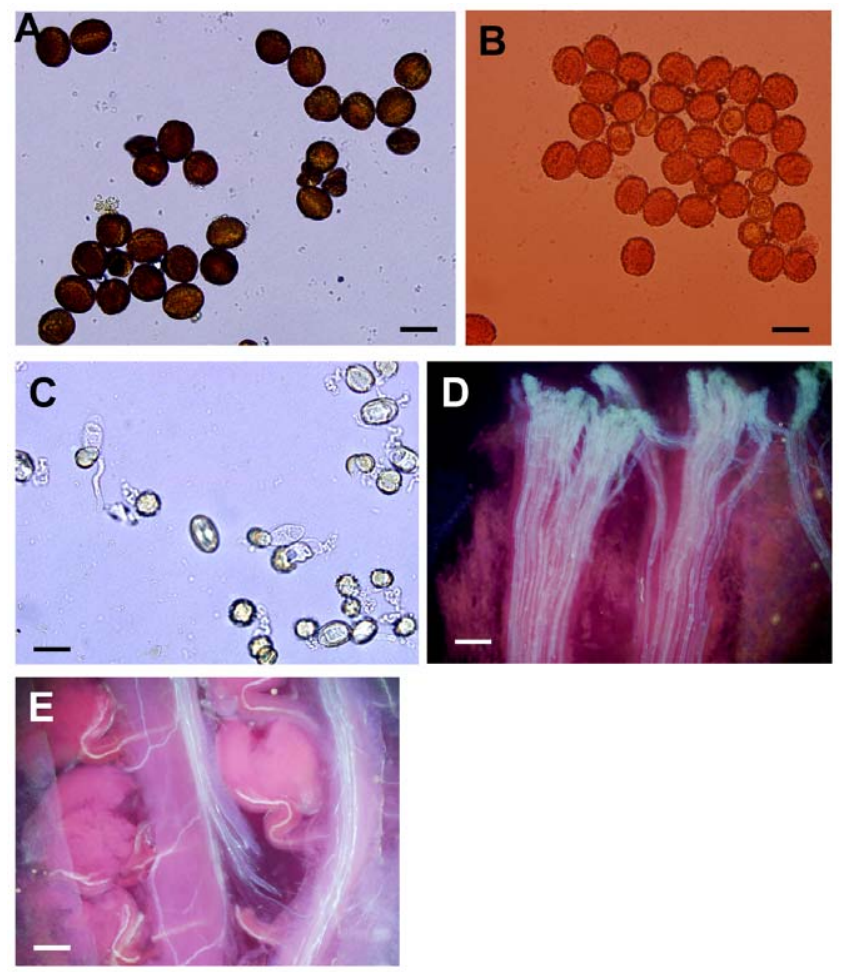

Figure 8. Determination of strong BnAP2-RNAi pollen viability, fertility and quality. A, Pollen grains stained with I2-KI. B, Viability of pollen by aceto-carmine staining. C, Pollen germination in vitro. D, Pollen germination on stigma stained with aniline blue. $E$, Germinating pollen tubes enter into ovules. Scale bars $=50 \mu \mathrm{m}$. doi:10.1371/journal.pone.0033890.g008 abortive seeds at $10 \mathrm{DAF}, 20 \mathrm{DAF}$ and $30 \mathrm{DAF}$ (days after fertilization), and protein accumulation stagnated at $20 \mathrm{DAF}$, whereas total protein content of wild type seeds increased gradually. Figure $11 \mathrm{~F}-\mathrm{K}$ shows longitudinal sections through cleared seeds at differently developmental stage, including at 10 DAF, $20 \mathrm{DAF}$ and $30 \mathrm{DAF}$, respectively. Strong BnAP2-RNAi and wild-type seeds initially did not display a significantly morphological difference at $10 \mathrm{DAF}$, suggesting female gametophytes of both genotypes were fertilized with similar efficiencies (Fig. 11, F and I). At $20 \mathrm{DAF}$, development of BnAP2-RNAi embryos was slower than wild type (Fig. 11, G and J). At $30 \mathrm{DAF}$, wild-type embryos were essentially at their final size (Fig. $11 \mathrm{~K}$ ), whereas BnAP2-RNAi embryos stopped growing and developing and gradually withered (Fig. 11H).

\section{Discussion}

\section{BnAP2 encodes an AtAP2 ortholog}

In this study, we reported the isolation and partial characterization of an AP2-like gene from B. napus, here named BnAP2. Sequence analysis and phylogenetic tree analysis showed that the $\mathrm{BnAP} 2$ protein was the closest AP2 homolog described so far and the homology between BnAP2 and AP2 extends throughout the whole protein. BnAP2 are broadly expressed in all four types of floral organs and other vegetative different tissues. Moreover, the expression in an ap2-11 mutant background in Arabidopsis resulted in functional complementation. Fusion protein of BnAP2 with GAL4 DNA binding domain strongly activated transcription in yeast, and the transactivating activity was localized to the $100 \mathrm{~N}$ terminal amino acids of BnAP2. Together with the sequence and expression data, the complementation data and transcriptional activity in yeast indicate that BnAP2 encodes an AtAP2 ortholog in B. napus.

\section{Suppression of $B n A P 2$ gene expression in homozygous BnAP2-RNAi lines}

Post-transcriptional gene silencing (PTGS) is a widely used gene suppression approach that selectively silences genes in plants and animals [33]. PTGS works through sequence-specific degradation of mRNA through endonucleolytic cleavage followed by exonuclease digestion [34] and is considered to have evolved in plants for protection against pathogenic RNAs [35]. There are increasing reports of constructs specifically designed to express dsRNA in plants, usually in the form of self-complementary hairpin RNA (hpRNA), eliciting a high degree and frequency of PTGS of invading viruses, reporter transgenes, and endogenous genes [2123,36,37].

Given that B. napus is thought to be a diploidized tetraploid, with many non-repetitive sequences in genome being present in more than two copies, RNAi is expected to be a powerful tool for 
Table 2. Fertility and seed weight analysis of BnAP2-RNAi plants.

\begin{tabular}{llllll}
\hline Genotype & Flower No. & Elongated Silique No. & Length Per Silique $(\mathbf{c m})$ & Seed No. Per Silique & Seed Weight*(mg) \\
\hline Wild type & $42 \pm 2.7$ & $42 \pm 2.7$ & $11.8 \pm 5.3$ & $20 \pm 2.3$ & $186^{\mathrm{A}}$ \\
BnAP2-RNAi-18 & $45 \pm 1.8$ & $40 \pm 3.2$ & $10.0 \pm 4.2$ & $6 \pm 3.4$ & $185^{\mathrm{A}}$ \\
BnAP2-RNAi-1 & $50 \pm 5.2$ & $8 \pm 3.4$ & $4.0 \pm 1.6$ & $5 \pm 3.8$ & $274^{\mathrm{B}}$ \\
BnAP2-RNAi-26 & $48 \pm 7.3$ & $10 \pm 5.1$ & $5.6 \pm 1.2$ & $5 \pm 2.4$ & $279^{\mathrm{B}}$ \\
\hline
\end{tabular}

All values pertain to the primary inflorescence. Plants were grown concurrently under identical conditions. Similar results were obtained in an independent experiment that was performed in a different season of the year. Means \pm SD are shown.

*Weight of seeds produced on primary inflorescence is given in mg per 50 seeds. Seed weight values that differ at the 0.05 significance level are labeled with $A$ and $B$ letters. Seed weights for wild type and BnAP2-RNAi-18 and values for BnAP2-RNAi-1 and BnAP2-RNAi-26 are not significantly different, respectively.

doi:10.1371/journal.pone.0033890.t002

genetic modification of such multiple-copy genes. Using intronspliced hairpin RNA (ihpRNA) as RNAi construct that targeted $B n A P 2$ gene, we totally obtained 6 transgenic lines. Although PCR-based screen and DNA gel blot confirmed the integration of foreign BnAP2-RNAi fragment into the genome of B. napus, 3 transgenic lines did not exhibit any morphological changes. RTPCR analysis showed there was no decrease in the mRNA of $B n A P 2$ in the buds of the corresponding RNAi lines. We speculated that transgenic silence led to the consequence. At the same time, BnAP2 gene expression could not be detected by RTPCR in other 3 transgenic plants, which indicated that there was specific and efficient suppression of target gene. Of which, two BnAP2-RNAi lines showed significant defects in flower organs and seed development, and one BnAP2-RNAi line only showed floral defects. These results demonstrated for the first time, to our knowledge, that ihpRNA constructs targeted against an endogenous target gene were clearly able to generate phenotypic changes in B. napus, making this approach an efficient technique for genetic modification of important agronomic traits in oil crops.

\section{Floral defects and reduced fertility induced in BnAP2- RNAi lines}

In Arabidopsis, the floral homeotic gene APETALA2 (AP2) controls three critical aspects of flower ontogeny, including the establishment of the floral meristem [38-42], the specification of floral organ identity [6-8], and the temporal and spatial regulation of floral homeotic gene expression $[43,44]$. Clearly, $A P 2$ plays a critical role in the regulation of Arabidopsis flower development. Null mutants of the AP2 gene in Arabidopsis confer a mutant phenotype that fit almost perfectly with the A-function in the ABC-model. The phenotypes described in the strong RNAi lines are in agreement with the notion that BnAP2 exert the A-function in $B$. napus. In this study, floral phenotype defectives in B. napus BnAP2-RNAi lines were observed, which was similar to those described in Arabidopsis. Weak BnAP2-RNAi line, having defects in petals and stamens, showed normal fertility. By contrast, two strong BnAP2-RNAi lines not only exhibited the loss of floral identity but also reduced fertility. Subsequent pollen stainability, pollen germination and reciprocal cross experiment indicated that pollens from strong BnAP2-RNAi lines had normal quality and viability. These results told us that knockdown of BnAP2 gene had no effect on pollen fertility and induced aberrant pistils maybe had a negative effect on female fertility. Nevertheless, we could not exclude the possibility that reduced fertility of the RNAi lines resulted from the suppression of other similar $A P 2$ genes, in addition to the $B n A P 2$ gene.

\section{$B n A P 2$ gene is involved in floral organ abscission and senescence}

In plants, abscission and senescence events allow the shedding of leaves, flowers, fruits and seeds, and can facilitate growth, reproduction, and defense against pathogens [45,46]. As with most developmental events, proper timing and spacing are crucial during organ separation [47]. Floral organ abscission is a

Table 3. Aberrant pistils leads to reduced fertility in strong BnAP2-RNAi plants.

\begin{tabular}{|c|c|c|c|c|c|}
\hline \multicolumn{2}{|l|}{ Parent } & \multirow[b]{2}{*}{ Flower No. } & \multirow[b]{2}{*}{ Elongated Silique No. } & \multirow[b]{2}{*}{ Length Per Silique (cm) } & \multirow[b]{2}{*}{$\begin{array}{l}\text { Seed No. } \\
\text { Per Silique }\end{array}$} \\
\hline Female & Male & & & & \\
\hline \multirow[t]{3}{*}{ Wild type } & Wild type & 10 & 10 & $12 \pm 2.3$ & $19 \pm 3.1$ \\
\hline & $B n A P 2-\mathrm{RNAi}-1$ & 10 & 10 & $11.6 \pm 3.3$ & $20 \pm 1.1$ \\
\hline & BnAP2-RNAi-26 & 10 & 10 & $11.4 \pm 4.5$ & $21 \pm 4.2$ \\
\hline \multirow[t]{2}{*}{ BnAP2-RNAi-1 } & $B n A P 2-R N A i-1$ & 10 & 3 & $6 \pm 2.6$ & $7 \pm 3.5$ \\
\hline & Wild type & 10 & 4 & $5.8 \pm 1.3$ & $3 \pm 2.6$ \\
\hline \multirow[t]{2}{*}{ BnAP2-RNAi-26 } & $B n A P 2-R N A i-26$ & 10 & 3 & $6 \pm 1.8$ & $4 \pm 2.7$ \\
\hline & Wild type & 10 & 4 & $5 \pm 3.2$ & $4.5 \pm 1.5$ \\
\hline
\end{tabular}

Reciprocal crosses between wild-type plants and strong ap2 mutant plants were performed on secondary inflorescences. Plants were grown together in the same conditions. Three flowers at identical positions (11th to 13th flowers for wild type or male-sterile mutant, 10th to 15 th flowers in ap 2 mutants) were manually pollinated. Two to four inflorescences per plant and four to five plants were used for calculations. Similar results were obtained in an independent experiment that was performed in a different season of the year. Means \pm SD are shown.

doi:10.1371/journal.pone.0033890.t003 
A

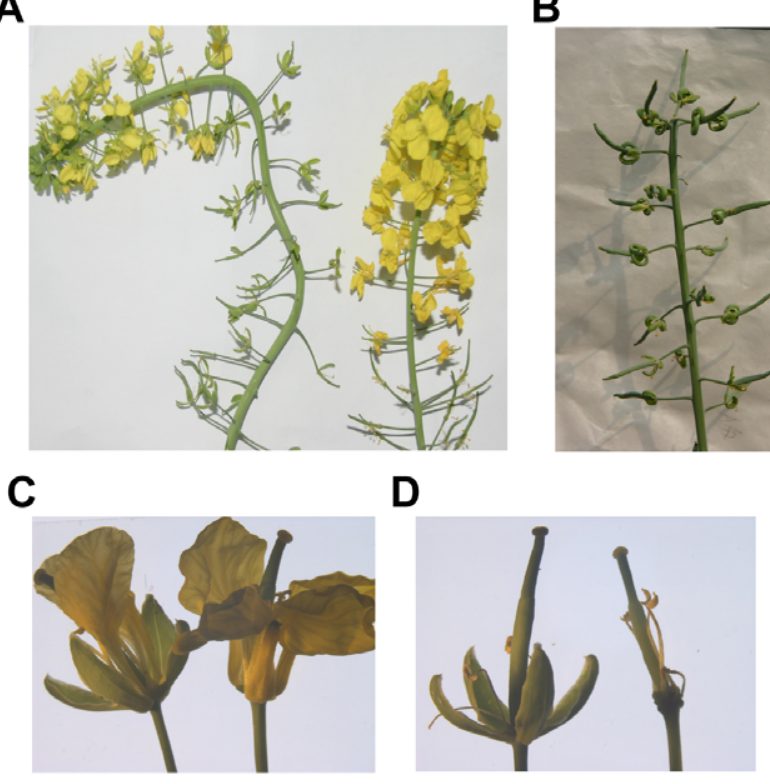

Figure 9. Senescence and abscission were delayed in strong BnAP2-RNAi lines. A, Floral organs abscission along the inflorescence in the wild type (WT) (right) and BnAP2-RNAi lines (left). B, Sepals in $B n A P 2-R N A i$ lines retained with silique development. $C$, On second day following pollination, sepals of the wild type demonstrated yellowing, in contrast, sepals of strong BnAP2-RNAi lines keep green. D, On third day following pollination, sepals of the wild type were detached, in contrast, sepals of strong BnAP2-RNAi lines remained. doi:10.1371/journal.pone.0033890.g009

developmentally controlled program that occurs after flower pollination. Ethylene is considered to be a fundamental regulator of the abscission rate $[31,48]$. Defects in the components of the ethylene perception and signaling pathways will delay abscission to various degrees. In Arabidopsis ethylene-insensitive mutants, such as etr1 and ein2, both floral organ abscission and senescence are

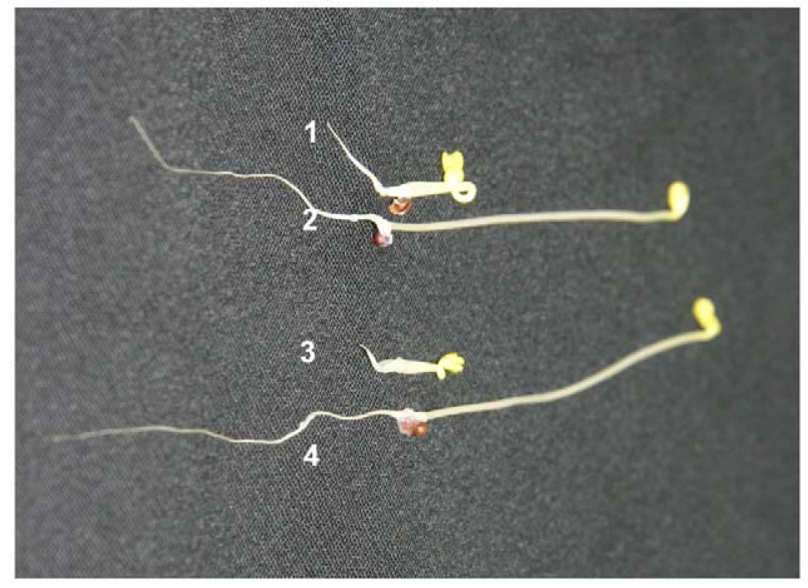

Figure 10. Triple response phenotype of wild-type and strong BnAP2-RNAi plants. The triple-response assay was conducted in growing seedlings of wild-type and strong BnAP2-RNAi-26 plants on vertical half-strength Murashige and Skoog (MS) agar plates in the absence or presence of $5 \mathrm{mM} \mathrm{ACC}$ at $25^{\circ} \mathrm{C}$ in the dark for $3 \mathrm{~d}$. 1, Seedling of wild-type plant in MS with ACC; 2, Seedling of wild-type plant in MS without ACC; 3, Seedling of BnAP2-RNAi-26 plant in MS with ACC; 4, Seedling of BnAP2-RNAi-26 plant in MS without ACC. doi:10.1371/journal.pone.0033890.g010 delayed $[31,46]$. However, abscission processes have been divided into ethylene-dependent and ethylene-independent types [31], and therefore further experiments would be carried to determine whether the BnAP2-RNAi plants have normal ethylene perception and response.

However, ethylene is not the only regulator of abscission, and abscission processes have been divided into ethylene-dependent and ethylene-independent types [31]. A ligand gene family, including INFLORESCENCE DEFICIENT IN ABSCISSION (IDA) and five IDALIKE (IDL) genes, participates in the control of abscission, and its function is not affected by exogenous ethylene $[49,50]$. In addition, some genes that relate leaf and floral organ patterning also influence the capacity for abscission. These genes include two well-known leaf-patterning factors, BOP1/BOP2 [51], a MADS box domain transcription factor, AGL15, and two chromatin regulators, ARP4 and ARP7 [52-54]. The tripleresponse assay of wild type and $B n A P 2-\mathrm{RNAi}-26$ plants confirmed that the BnAP2-RNAi plants had normal ethylene perception and response. And the result suggested that BnAP2 gene had an effect on sepal abscission with the ethylene-independent pathway. At the same time, we could not exclude the possibility that delayed sepal abscission and senescence of the RNAi lines was caused by the inhibition of other similar AP2 genes, in addition to the BnAP2 gene.

\section{Knockdown of BnAP2 gene expression disordered seed development}

Our analysis of BnAP2 gene expression at the RNA level revealed that $B n A P 2$ was expressed in both nonfloral and floral tissues and organs. We therefore proposed that BnAP2 had a more expanded role in $B$. napus growth and development. In strong $B$. napus BnAP2-RNAi lines, dried, full and mature seeds produced through self-pollinating were larger and more variable in shape than circle-formed wild-type seeds because of knockdown of $B n A P 2$ gene. In addition, some full and mature seed coat development was affected, leading to the radicles exposed to seed coat.

Seed development in higher plants begins with a double fertilization process that occurs within the ovule and ends with a dormant seed primed to become the next plant generation $[55,56]$. Many transcription factors ( $\mathrm{TFs}$ ) are responsible for controlling seed development. Le et al. [57] carried global analysis of gene activity during Arabidopsis seed development and identified 289 seed-specific genes, including 48 that encode TFs. In Arabidopsis, $A P 2$ was involved in controlling ovule, seed coat development, seed size and seed development [10-12,41,58]. Then, these results suggested that $B n A P 2$ gene played an important role in seed development.

Study of abortive seed development in B. napus BnAP2-RNAi lines further confirmed above proposal. The seed consists of three major compartments, the embryo, endosperm and seed coat, that originate from different cells of the ovule and possess different complements of maternal and paternal genomes [59]. Seed development proceeds through two distinct phases during which growth of the three compartments is coordinated. During the early morphogenesis phase, the embryo undergoes a series of differentiation events in which the plant body plan is established with the formation of embryonic tissue and organ systems. It is also during this phase that the endosperm mother cell initially undergoes nuclear division without cytokinesis to form a syncytium [60]. Syncytial nuclei are sequestered into individual endosperm cells through the process of cellularization, and the endosperm continues to grow through periclinal cell divisions at the periphery of the endosperm. Later in embryogenesis during the maturation 

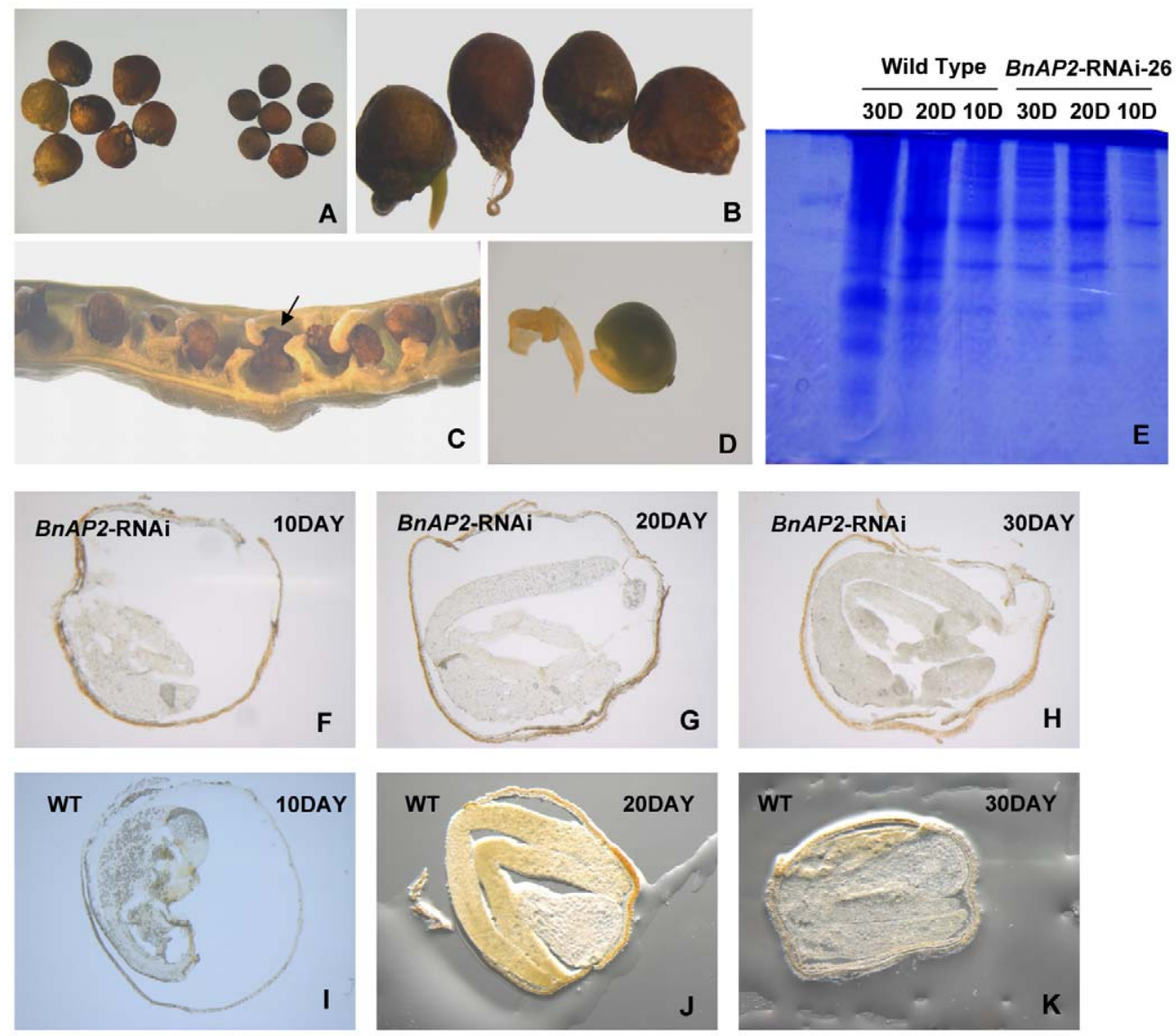

Figure 11. Strong BnAP2-RNAi lines cause changes in seed development. A, Seeds of BnAP2-RNAi lines are less round in shape and larger in size than that of wild type (left, BnAP2-RNAi; right, wild type). B, The surface of the full BnAP2-RNAi seed is bumpy and radicels drill out from mature seeds. C, Abortive seeds in strong BnAP2-RNAi lines (arrow). D, Embryo of abortive seeds (left, BnAP2-RNAi; right, wild type). E, BnAP2-RNAi-26 plant seeds contain less protein than do wild-type seeds. Protein extracts from an equal number of wild-type and BnAP2-RNAi-26 seeds were fractionated on a $12 \%$ SDS polyacrylamide gel and stained. Molecular mass markers are shown to the left of the gel. Optical sections through developing BnAP2RNAi $(\mathrm{F}-\mathrm{H})$ and wild-type seeds (I-K) at the indicated DAP. Seeds from three to five siliques at each time point were harvested, fixed and cleared and representative optical sections are shown. doi:10.1371/journal.pone.0033890.g011

phase, the embryo and endosperm accumulate reserves such as storage lipids and proteins, and the embryo acquires the ability to withstand desiccation $[61,62]$. In plants such as B. napus, the endosperm is largely consumed by the developing embryo such that only a few endosperm cell layers remain in the mature seed. In B. napus BnAP2-RNAi lines, total protein content of abortive seeds showed no conspicuous alterations at $10 \mathrm{DAF}, 20 \mathrm{DAF}$ and 30 DAF. This result suggested that there was an obstacle in accumulating reserves such as proteins in embryogenesis during the maturation phase. Frozen section analysis revealed that during the early morphogenesis phase of abortive seeds, the embryo successfully undergoes a series of differentiation events in which the plant body plan was established with the formation of embryonic tissue and organ systems. But embryos established did not successfully develop into normal and full seeds, stopping growing at $20 \mathrm{DAF}$. Together, loss of BnAP2 function influenced seed development in embryogenesis during the maturation phase.

In conclusion, as a key transcriptional factor, $B n A P 2$ gene is involved in the regulation of many target genes and plays essential roles in floral identity, sepal abscission and senescence, and seed development in B. napus. Since the RNAi lines, in addition to the $B n A P 2$ gene, also affected the expression of other similar AP2 genes, we could not exclude the possibility that reduced fertility and delayed sepal abscission and senescence was led by the suppression of other paralogues. And further experiment would be conducted in order to screen paralogues affected in the RNAi lines through transcriptome profiling. Although knockdown of BnAP2 gene caused mature and full seeds to be larger than wild seeds, total seed yield could not be raised in BnAP2-RNAi lines because of reduced female fertility and abortive seed. However, it is unclear how BnAP2 acts to affect seed development. Additional experiments are needed to understand how BnAP2 affects seed development and seed size at a mechanistic level. To unravel the genes that might be directly or indirectly regulated by $B n A P 2$ in $B$. napus, further research would be focused on comparing gene expression of seed development between wild type and transgenic knockdown plants through transcriptome profiling.

\section{Materials and Methods}

\section{Isolation and sequencing of the BnAp2 gene}

Total RNA was extracted from the flower buds of $B$. napus cultivar Zhongshuang 9 using the RNeasy Plant Mini Kit (Qiagen, USA) and first-strand cDNA was synthesized following the procedure described by SMART ${ }^{\mathrm{TM}}$ PCR cDNA Synthesis Kit (Clontech, TaKaRa) and was used as a template. Two specific 
primers $\mathrm{P} 1$ and $\mathrm{P} 2$ (Table S1) were designed based on the known $A P 2$ gene sequence of $A$. thaliana. PCR reaction was performed as follows, firstly denatured at $94^{\circ} \mathrm{C}$ for $2 \mathrm{~min}$, then $94^{\circ} \mathrm{C} 30 \mathrm{~s}, 64^{\circ} \mathrm{C}$ $30 \mathrm{~s}, 72^{\circ} \mathrm{C} 90 \mathrm{~s}$ for 14 cycles and the annealing temperature decreased $1^{\circ} \mathrm{C}$ every cycle, then $94^{\circ} \mathrm{C} 30 \mathrm{~s}, 50^{\circ} \mathrm{C} 30 \mathrm{~s}, 72^{\circ} \mathrm{C} 90 \mathrm{~s}$ for 22 cycles, and then $72^{\circ} \mathrm{C} 5 \mathrm{~min}$. The specific fragment obtained was cloned into the pMD18-T vector (TaKaRa, Japan) and sequenced at Beijing Huada Company (China).

\section{RT-PCR}

Total RNA was isolated from root, shoot, leaf, flower bud, silique (including peel and seed) and four types of floral organs using the RNeasy Plant Mini Kit (Qiagen, USA), respectively. And then, RNA was treated with DNase, extracted with phenol/ chloroform, and precipitated, and $0.5 \mu \mathrm{g}$ of total RNA was reverse transcribed from an oligo-dT primer by using the SuperScript ${ }^{\circledR}$ III First-Strand Synthesis System (Invitrogen). The first-strand cDNA was used as a template for RT-PCR amplification with corresponding primers (Table S1).

\section{PCR-based screening and southern-blot analysis}

Genomic DNA was extracted from fresh leaf tissues of in vitrogrown Kan-positive plants and untransformed control plants by the cetyltrimethylammonium bromide (CTAB) method [63]. For transgenic detection, PCR-based screening was used to maintain the presence of the transgene. Specific primers for the $\mathcal{N} p t I I$ gene: P19 and P20 were used (Table S1). These primers were expected to give products of $600 \mathrm{bp}$. PCR analysis was done according to the method reported by $\mathrm{Yu}$ et al. [64]. For Southern blot analysis which confirmed the integration of the target gene, the probe was specific to the $35 \mathrm{~S}$ promoter. The primers used for the $35 \mathrm{~S}$ promoter probe were P21 and P22 (Supplemental Table S1), which amplified a 756-bp product. For Southern blot analysis which detected copy number of BnAP2 gene, the probe was specific to the $B n A P 2$ gene. The primers used for the $B n A P 2$ gene probe were $\mathrm{P} 1$ and $\mathrm{P} 2$ (Table S1), which amplified full BnAP2 gene product. Total thirty micrograms of genomic DNA were digested with appropriate restriction enzyme. The restriction fragments were size-fractionated by $0.8 \%(\mathrm{w} / \mathrm{v})$ agarose gel electrophoresis and transferred to a Hybond- $\mathrm{N}^{+}$nylon membrane (Amersham Pharmacia Biotech, UK). The labeling of probe, prehybridization, hybridization and detection were performed following the procedures described by DIG High Prime DNA Labeling and Detection Starter Kit II (Roche Diagnostics GmbH, Germany).

\section{Vector construction}

BnAP2 gene over-expressing vector used to transform Arabidopsis was constructed by PCR using the synthetic oligonucleotide primers P6 and P7 (Supplemental Table S1). The amplified fulllength $B n A P 2$ cDNA fragment was digested with $B g / I I$, then cloned into pBI121 [65], which had been cut with BamHI. The resulting $B n A P 2$-expressing vector was designated as pBI121-BnAP2.

Vector construction for RNAi knockout, RNAi vector pHANNIBAL [23] was used to generate RNAi constructs. The sense and antisense cDNA sequences of the BnAP2 gene were amplified from CDS of BnAP2 cDNA through PGR and placed under the control of a constitutively expressing $35 \mathrm{~S}$ promoter in PHANNIBAL. The sense fragment was amplified using gene specific primers having restriction sites $E_{c o \mathrm{RI}}(\mathrm{P} 15)$ and $K p n \mathrm{I}(\mathrm{P} 16)$ and inserted as an $E c o$ RI- $K p n$ I fragment into pHANNIBAL which was cut with $E c o$ RI and $K p n \mathrm{I}$ (Supplemental Table S1). The antisense fragment was amplified using gene-specific primers having restriction sites $\mathrm{Xba \textrm {I }}$ (P17) and BglII (P18) and was inserted as an inverted fragment as $X b a$ - $B g l I I$ pHANNIBAL which was cut with $X b a \mathrm{I}$ and BamHI
(Supplemental Table S1). The pHANNIBAL vector was then subcloned at $\mathcal{N}$ otI sites into a binary vector pART27 [66].

For construction of various BnAP2 deletion mutants and full $B n A P 2$ for transactivation activity assays, the deletion mutant genes were generated by PCR using restriction sites within the synthetic oligonucleotide primers. The primers were shown in Table S1. The forward primers carried $E_{c o} \mathrm{RI}$ and the reverse primers had BglIII. The restriction sites used in the primers to facilitate the cloning of the PCR product into the yeast GAL4 DNA binding domain vector pGBKT7 were underlined. pGBKT7 was cut with EcoRI and BamHI. The plasmids pBnAP2 $\Delta \mathrm{C} 1, \mathrm{pBnAP} 2 \Delta \mathrm{C} 2, \mathrm{pBnAP} 2 \Delta \mathrm{C} 3, \mathrm{pBnAP} 2 \Delta \mathrm{C} 4$ and pBnAP2 $\Delta$ C5, encoded BnAP2 proteins with deletion of 59, 119, 179, 232 and 332 C-terminal amino acids, respectively. The plasmid pBnAP2 $\triangle \mathrm{N} 1$ encoded $\mathrm{BnAP} 2$ proteins with deletion of $100 \mathrm{~N}$-terminal amino acids. The plasmid pBnAP2 which encoded full BnAP2 protein was generated by PCR with $\mathrm{P} 6$ and $\mathrm{P} 14$.

\section{Plant transformation (Arabidopsis complement experiment, $B$. napus transformation)}

For Arabidopsis transformation, the Arabidopsis ap2-11 mutant (kindly provided by John J. Harada) was transformed according to the vacuum infiltration method [67] using Agrobacterium strain EHA105. T3- or T4-generation homozygous plants were used for phenotype analysis.

Agrobacterium-mediated transformation of B. napus cultivar Zhongshuang 6 was performed according to the protocol described previously [29]. Kanamycin-resistant plantlets that rooted well in selective medium were transferred to pots and grown in a glasshouse. For plants grown in a plant growth room, the growth conditions were $20 \pm 2^{\circ} \mathrm{C}$ under a $16 / 8 \mathrm{~h}$ photoperiod at a light intensity of $44 \mathrm{umol} \mathrm{m} \mathrm{m}^{-2} \mathrm{~s}^{-1}$ and $60-90 \%$ relative humidity. For plants sown in a glasshouse, the conditions were 14 $22^{\circ} \mathrm{C}$ and natural light.

\section{Ethylene response}

Ethylene treatment was performed as described previously [68]. For the triple response, $5 \mathrm{mM}$ of the ethylene precursor ACC was added to Murashige and Skoog (MS) medium for germination of wild-type or transgenic seeds in the dark for $3 \mathrm{~d}$.

\section{Transactivation activity assays}

For the yeast strains and transformation, the yeast strain Saccharomyces cerevisiae strain AH109 (MATa, HIS3, lacZ, ADE2, MEL1) was transformed with plasmids containing CDS of BnAP2 cDNA or BnAP2 fragments which were fused in frame to the yeast GAL4 DNA binding domain vector pGBKT7, using a modified lithium acetate procedure [69]. Transformants were selected on plates containing synthetic medium lacking tryptophan. The colony lift filter assay and liquid culture assay using onitrophenyl- $\beta$-D-galactopyranoside as a substrate were performed subsequently as described by the manufacturer (Clontech, Palo Alto, CA) to determine the ability of each translation product to activate transcription.

For the filter lift $\beta$-galactosidase assay, transformants were streaked onto a synthetic complete supplement (SC)-Trp-His-ADE medium, grown at $30^{\circ} \mathrm{C}$ for $3 \mathrm{~d}$, and lifted from the medium using filter papers (Whatman No.5). The filters were immersed into liquid nitrogen for $30 \mathrm{~s}$, thawed at room temperature for $5 \mathrm{~min}$, and placed on filter papers soaked with an X-gal $(0.5 \mathrm{mg} / \mathrm{ml})$ solution. The reactions were stopped after 2 to 4 hours at $30^{\circ} \mathrm{C}$. For each construct, 3 independent transformants were assayed. 
For the liquid $\beta$-galactosidase assay, colonies of yeast transformants were grown in an SC-Trp-His-ADE medium to an $\mathrm{A}_{600}$ of approximately 0.5 . The cultures were diluted 4 times with fresh media and grown further for $3 \mathrm{~h}$. After the $\mathrm{A}_{600}$ was measured, $1.5-\mathrm{ml}$ aliquots of the cultures briefly underwent centrifugation in a microfuge. The pellets were resuspended in $0.5 \mathrm{ml}$ of Z-buffer $\left(60 \mathrm{mM} \mathrm{Na}_{2} \mathrm{HPO}_{4}, 40 \mathrm{mM} \mathrm{NaH} \mathrm{PO}_{4}, 10 \mathrm{mM} \mathrm{KCL}\right.$, and $1 \mathrm{mM}$ $\left.\mathrm{MgSO}_{4} \cdot 7 \mathrm{H}_{2} \mathrm{O}\right)$ without $\beta$-mercaptoethanol, microfuged briefly again, and resuspended in $0.3 \mathrm{ml}$ of Z-buffer. One third of the suspension was transferred to a fresh tube, placed in liquid nitrogen until frozen, and thawed in a $37^{\circ} \mathrm{C}$ water bath. The freeze-thaw cycle was repeated 2 more times. Afterward, $0.7 \mathrm{ml}$ of Z-buffer with $\beta$-mercaptoethanol and $0.16 \mathrm{ml}$ of o-nitrophenyl- $\beta$ D-galactopyranoside (ONPG) $(4 \mathrm{mg} / \mathrm{ml}$ in Z-buffer) were added to start the reaction. Incubation was continued at $30^{\circ} \mathrm{C}$ until the color changed to yellow. Reactions were stopped by the addition of $0.4 \mathrm{ml}$ of $1 \mathrm{M} \mathrm{Na}_{2} \mathrm{CO}_{3}$. The mixtures underwent microcentrifugation for $10 \mathrm{~min}$ to remove cell debris, and the $\mathrm{A}_{420}$ was measured. Four independent transformants were assayed for each construct, and the $\beta$-galactosidase activity was expressed in Miller units.

\section{Determination of pollen viability, fertility and quality}

Pollen viability test was performed with the use of two staining procedures, one reported by Shinjyo [70] and the other by Wei et al. [71], and in vitro pollen germination. Newly opened flowers were sampled at 9-10 a.m. Anthers were squashed and pollen grains were stained with $1 \% \mathrm{w} / \mathrm{v}$ iodine/potassium iodide solution (I2-KI) to observe starch accumulation or with $1 \%$ aceto-carmine, and were observed under microscopy. Five individual plants of each material and five flowers of each plant were used and the calculation was based on 200 pollen grains of each flower. Pollen viability rate was calculated as the number of well-stained pollen grains/total pollen grains $\times 100 \%$. For pollen germination in vitro, pollen grains was isolated from flowers of strong BnAP2-RNAi lines and immediately germinated in vitro using Hodgkins and Lyons media containing $9 \%$ sucrose and $13 \%$ polyethylene glycol (MW 4000) [72]. The pollen was incubated in light and high humidity for $6 \mathrm{~h}$ at $23^{\circ} \mathrm{C}$. Germinating pollen (those with pollen tubes greater than twice the length of the pollen grain) were counted and photographed. Pollen germination on the stigmas was observed using aniline blue staining as previously described [73]. Briefly, $3 \mathrm{~h}$ after pollination, pistils were fixed with ethanol/acetic acid (3:1 v/v) for $30 \mathrm{~min}$, washed with $1 \mathrm{~N} \mathrm{KOH}$ at $55^{\circ} \mathrm{C}$ for $30 \mathrm{~min}$, and stained with $1 \% \mathrm{w} / \mathrm{v}$ aniline blue for $40 \mathrm{~min}$ at $37^{\circ} \mathrm{C}$. Pollen fertility of $B n A P 2$ RNAi mutants was also assessed according to reciprocal crosses between Zhongsuang 6 wild-type plants and BnAP2-RNAi mutants. Plants were grown together in the same conditions. Flowers at identical positions were manually pollinated. Two to four inflorescences per plant and four to five plants were used for calculations. Similar results were obtained in an independent experiment.

\section{Protein analysis}

Ten seeds from Zhongshuang 6 wild-type plants or BnAP2RNAi lines, at $10 \mathrm{DAY}, 20 \mathrm{DAY}, 30 \mathrm{DAY}$, respectively, were

\section{References}

1. Lohmann JU, Weigel D (2002) Building beauty: the genetic control of floral patterning. Dev Cell 2: 135-142.

2. Jack T (2004) Molecular and genetic mechanisms of floral control. Plant Cell 16: S1-17.

3. Krizek BA, Fletcher JC (2005) Molecular mechanism of flower development: an armchair guide. Nat Rev Genet 6: 688-698.

4. Koornneef M, de Bruine JH, Goettsch P (1980) A provisional map of chromosome 4 of Arabidopsis. Arabidopsis Inf Serv 17: 11-18. homogenized with $100 \mathrm{ul}$ of extraction buffer [74] by using a microglass pestle and mortar, respectively. After centrifugation, $10 \mathrm{ul}$ of each extract was used for SDS-PAGE [75]. Protein content in $5 \mu \mathrm{l}$ of each extract was determined by using the BioRad RC-DC Protein Assay Kit with BSA as the standard.

\section{Western blot analysis}

Protein extracts of flower buds, floral organs in whirl 3 and 4, respectively, were prepared according to the method described above. The concentration of protein in the supernatant was quantified using a protein assay kit (Bio-Rad). Proteins were separated by $10 \%$ sodium dodecyl sulfatepolyacrylamide gel electrophoresis (SDS-PAGE) and electrotransferred to nitrocellulose membranes. The membranes were probed with a goat polyclonal AtAP2 antibody (Santa Cruz), followed by incubation with horseradish peroxidase conjugated donkey anti-goat IgG (Santa Cruz). Immunoreactivity was visualized by chemiluminescent detection (Pierce). Immunoblots were visualized with the ECL detection system (Pierce).

\section{Phylogenetic Analysis}

To detect BnAP2 homolog in A. thaliana, all the protein sequences of AP2-domain genes in $A$. thaliana were downloaded from RARTF database (http://rarge.psc.riken.jp/rartf/) [76]. Selected 145 Arabidopsis AP2-domain genes and target BnAP2 were used to constructed phylogenetic trees with the MEGA5.0 software package [77-80]. Phylogenetic relationship was inferred using the Neighbor-Joining method and evolutionary distances were computed using the p-distance method.

\section{Frozen section}

Seeds at different developmental phase were fixed with FAA (10\% formalin $/ 5 \%$ acetic acid $/ 45 \%$ ethanol $/ 0.01 \%$ Triton X100) for $45 \mathrm{~min}$, and rehydrated through an ethanol series. Seeds were then embedded in OCT compound and frozen, sectioned at $10-\mu \mathrm{m}$ thickness with frozen section machine Leica CM1850 (Germany). Observations were made with an Olympus microscope and photographed.

\section{Supporting Information}

Table S1 List of primers used. (PDF)

\section{Acknowledgments}

Thanks to Prof. John J. Harada (Section of Plant Biology, Division of Biological Sciences, University of California, One Shields Avenue, Davis, CA 95616) for providing us with the ap2-11 mutant of Arabidopsis.

\section{Author Contributions}

Conceived and designed the experiments: WW XY. Performed the experiments: XY LZ BC. Analyzed the data: ZX GG JY. Contributed reagents/materials/analysis tools: LW CL WW. Wrote the paper: XY CL WW.

5. Jofuku KD, den Boer BGW, Van Montagu M, Okamuro JK (1994) Control of Arabidopsis flower and seed development by the homeotic gene APETALA2. Plant Cell 6: 1211-1225.

6. Komaki MK, Okada K, Nishino E, Shimura Y (1988) Isolation and characterization of novel mutants of Arabidopsis thaliana defective in flower development. Development 104: 195-203.

7. Kunst L, Klenz JE, Martinez-Zapater J, Haughn GW (1989) Ap2 gene determines the identity of perianth organs in flowers of Arabidopsis thaliana. Plant Cell 1: 1195-1208. 
8. Bowman JL, Smyth DR, Meyerowitz EM (1989) Genes directing flower development in Arabidopsis. Plant Cell 1: 37-52.

9. Bowman JL, Smyth DR, Meyerowitz EM (1991) Genetic interactions among floral homeotic genes of Arabidopsis. Development 112: 1-20.

10. Ohto MA, Floyd SK, Fischer RL, Goldberg RB, Harada JJ (2009) Effects of APETALA2 on embryo, endosperm, and seed coat development determine seed size in Arabidopsis. Sex Plant Reprod 22: 277-289.

11. Jofuku KD, Omidyar PK, Gee Z, Okamuro JK (2005) Control of seed mass and seed yield by the floral homeotic gene APETALA2. Proc Natl Acad Sci USA 102: 3117-3122.

12. Ohto M, Fischer RL, Goldberg RB, Nakamura K, Harada JJ (2005) Control of seed mass by APETALA2. Proc Natl Acad Sci USA 102: 3123-3128.

13. Würschum T, Grob-Hardt R, Laux T (2006) APETALA2 regulates the stem cell niche in the Arabidopsis shoot meristem. Plant Cell 18: 295-307.

14. Aukerman MJ, Sakai H (2003) Regulation of flowering time and floral organ identity by a microRNA and its APETALA2-like target genes. Plant Cell 15: 2730-2741.

15. Maes T, Van de Steene N, Zethof J, Karimi M, D'Hauw M, et al. (2001) Petunia Ap2-like genes and their role in flower and seed development. Plant Cell 13: 229-244.

16. Keck E, McSteen P, Carpenter R, Coen E (2003) Separation of genetic functions controlling organ identity in flowers. EMBO J 22: 1058-1066.

17. Karlova R, Rosin FM, Busscher-Lange J, Parapunova V, Do PT, et al. (2011) Transcriptome and metabolite profiling show that APETALA2a is a major regulator of tomato fruit ripening. Plant Cell 23: 923-941.

18. Baulcombe D (2005) RNA silencing. Trends Biochem Sci 30: 290-293.

19. Fire A, Xu S, Montgomery MK, Kostas SA, Driver SE, et al. (1998) Potent and specific genetic interference by double stranded RNA in Caenorhabditis elegans. Nature 391: 806-811.

20. Takagi K, Nishizawa K, Hirose A, Kita A, Ishimoto M (2011) Manipulation of saponin biosynthesis by RNA interference-mediated silencing of $\beta$-amyrin synthase gene expression in soybean. Plant Cell Rep 30: 1835-1846.

21. Waterhouse PM, Michael WG, Wang MB (1998) Virus resistance and gene silencing in plants can be induced by simultaneous expression of sense and antisense RNA. Proc Natl Acad Sci USA 95: 13959-13964.

22. Smith NA, Singh SP, Wang MB, Stoutjesdijk PA, Green AG, et al. (2000) Total silencing by intron-spliced hairpin RNAs. Nature 407: 319-320.

23. Wesley SV, Helliwell CA, Smith NA, Wang M, Rouse DT, et al. (2001) Construct design for effective and high-throughput gene silencing in plants. Plant J 27: 581-590.

24. Helliwell C, Waterhouse P (2005) Constructs and methods for hairpin RNAmediated gene silencing in plants. Methods Enzymol 392: 24-35.

25. Nizampatnam NR, Dinesh Kumar V (2011) Intron hairpin and transitive RNAi mediated silencing of orfH522 transcripts restores male fertility in transgenic male sterile tobacco plants expressing orfH522. Plant Mol Biol 76: 557-573.

26. Wang EM, Wagner GJ (2003) Elucidation of the functions of genes central to diterpene metabolism in tobacco trichomes using posttranscriptional gene silencing. Planta 216: 686-691.

27. Wang P, Liang Z, Zeng J, Li W, Sun X, et al. (2008) Generation of tobacco lines with widely different reduction in nicotine levels via RNA silencing approaches. J Biosci 33: 177-184.

28. Nagaharu U (1935) Genome analysis in Brassica with special reference to the experimental formation of B. napus and peculiar mode of fertilization. Jap J Bot 7: $389-452$

29. De Block M, De Brouwer D, Tenning P (1989) Transformation of Brassica napus and Brassica oleracea using Agrobacterium tumefaciens and the expression of the bar and neo genes in transgenic plants. Plant Physiol 91: 694-701.

30. Ohad N, Margossian L, Hsu YC, Williams C, Repetti P, et al. (1996) A mutation that allows endosperm development without fertilization. Proc Natl Acad Sci USA 93: 5319-5324.

31. Patterson SE, Bleecker AB (2004) Ethylene-dependent and -independent processes associated with floral organ abscission in Arabidopsis. Plant Physiol 134: 194-203.

32. Kieber JJ, Rothenberg M, Roman G, Feldmann KA, Ecker JR (1993) CTR1, a negative regulator of the ethylene response pathway in Arabidopsis, encodes a member of the Raf family of protein kinases. Cell 72: 427-441.

33. Watson JM, Fusaro AF, Wang M, Waterhouse PM (2005) RNA silencing platforms in plants. FEBS Lett 579: 5982-5987.

34. Van Eldik G, Litiere K, Jacobs J, Van Montagu M, Cornelissen M (1998) Silencing of beta-1,3-glucanase genes in tobacco correlates with an increased abundance of RNA degradation intermediates. Nucleic Acids Res 26: 5176-5181.

35. Marathe R, Anandalakshmi R, Smith TH, Pruss GJ, Vance VB (2000) RNA viruses as inducers, suppressors and targets of post-transcriptional gene silencing. Plant Mol Biol 43: 295-306.

36. Chuang CH, Meyerowitz EM (2000) Specific and heritable genetic interference by double-stranded RNA in Arabidopsis thaliana. Proc Natl Acad Sci USA 97: 4985-4990.

37. Wang MB, Abbott D, Waterhouse PM (2000) A single copy of a virus derived transgene encoding hairpin RNA gives immunity to barley yellow dwarf virus. Mol Plant Pathol 1: 401-410.

38. Irish VF, Sussex IM (1990) Function of the apetala-1 gene during Arabidopsis floral development. Plant Cell 2: 741-753.
39. Huala E, Sussex IM (1992) EAFY interacts with floral homeotic genes to regulate Arabidopsis floral development. Plant Cell 4: 901-913.

40. Bowman JL, Alvarer J, Weigel D, Meyerowitz EM, Smyth DR (1993) Control of flower development in Arabidopsis thaliana by APE TALA1 and interacting genes. Development 119: 721-743.

41. Schultz EA, Haughn GW (1993) Genetic analysis of the floral initiation process (FLIP) in Arabidopsis. Development 119: 745-765.

42. Shannon S, Meeks-Wagner DR (1993) Genetic interactions that regulate inflorescence development in Arabidopsis. Plant Cell 5: 639-655.

43. Bowman JL, Drews GN, Meyerowitz EM (1991) Expression of the Arabidopsis floral homeotic gene AGAMOUS is restricted to specific cell types late in flower development. Plant Cell 3: 749-758.

44. Drews GN, Bowman JL, Meyerowitz EM (1991) Negative regulation of the Arabidopsis homeotic gene AGAMOUS by the APETALA2 product. Cell 65: 991-1002.

45. Roberts JA, Elliott KA, Gonzalez-Carranza ZH (2002) Abscission, dehiscence, and other cell separation processes. Annu Rev Plant Biol 53: 131-158.

46. Lewis MW, Leslie ME, Liljegren SJ (2006) Plant separation: 50 ways to leave your mother. Curr Opin Plant Biol 9: 59-65.

47. Roberts JA, González-Carranza ZH (2007) Abscission. In Handbook of Plant Science, Volume 1 (ed. K. Roberts), pp.512-519. Chichester: John Wiley \& Sons. pp 512-519.

48. Taylor JE, Whitelaw CA (2001) Signals in abscission. New Phytol 151: 323-340.

49. Stenvik GE, Butenko MA, Urbanowicz BR, Rose JKC, Aalen RB (2006) Overexpression of INFLORESCENCE DEFICIENT IN ABSCISSION activates cell separation in vestigial abscission zones in Arabidopsis. Plant Cell 18: $1467-1476$.

50. Stenvik GE, Tandstad NM, Guo Y, Shi CL, Kristiansen W, et al. (2008) The EPIP peptide of INFLORESCENCE DEFICIENT IN ABSCISSION is sufficient to induce abscission in Arabidopsis through the receptor-like kinases HAESA and HAESA-LIKE2. Plant Cell 20: 1805-1817.

51. McKim SM, Stenvik GE, Butenko MA, Kristiansen W, Cho SK, et al. (2008) The BLADE-ON-PETIOLE genes are essential for abscission zone formation in Arabidopsis. Development 135: 1537-1546.

52. Fernandez DE, Heck GR, Perry SE, Patterson SE, Bleecker AB, et al. (2000) The embryo MADS domain factor AGL15 acts postembryonically: inhibition of perianth senescence and abscission via constitutive expression. Plant Cell 12: 183-198.

53. Kandasamy MK, Deal RB, McKinney EC, Meagher RB (2005) Silencing the nuclear actin-related protein AtARP4 in Arabidopsis has multiple effects on plant development, including early flowering and delayed floral senescence. Plant J 41: 845-858.

54. Kandasamy MK, McKinney EC, Deal RB, Meagher RB (2005) Arabidopsis ARP7 is an essential actin-related protein required for normal embryogenesis, plant architecture, and floral organ abscission. Plant Physiol 138: 2019-2032.

55. Goldberg RB, de Paiva G, Yadegari R (1994) Plant embryogenesis: Zygote to seed. Science 266: 605-614.

56. Raghavan V Double fertilization: Embryo and endosperm development in flowering plants (Springer, Berlin)

57. Le BH, Cheng C, Bui AQ, Wagmaister JA, Henry KF, et al. (2010) Global analysis of gene activity during Arabidopsis seed development and identification of seed-specific transcription factors. Proc Natl Acad Sci USA 107: 8063-8070.

58. Okamuro JK, den Boer BGW, Jofuku KD (1993) Regulation of Arabidopsis flower development. Plant Cell 5: 1183-1193.

59. Bewley JD, Black M (1994) Seeds: physiology of development and germination. Plenum Publishing Corporation, New York.

60. Brown RC, Lemmon BE, Nguyen H, Olsen OA (1999) Development of endosperm in Arabidopsis thaliana. Sex Plant Reprod 12: 32-42.

61. Harada JJ (1997) Seed maturation and control of germination. In: Larkins BA, Vasi IK (eds) Advances in cellular and molecular biology of plants. Cellular and molecular biology of seed development, vol 4. Kluwer Academic Publishers, Dordrecht. pp 545-592.

62. Vicente-Carbajosa J, Carbonaro P (2005) Seed maturation: developing an intrusive phase to accomplish a quiescent state. Int J Plant Sci 49: 645-651.

63. Saghai-Maroof MA, Soliman KM, Jorgensen RA, Allard RW (1984) Ribosomal DNA space length polymorphisms in barley: Mendelian inheritance, chromosomal locations and population dynamics. Proc Natl Acad Sci 81: 8014-8018.

64. Yu B, Zhai H, Wang YP, Zang N, He SZ, et al. (2007) Efficient Agrobacterium tumefaciens-mediated transformation using embryogenic suspension cultures in sweet potato, Ipomoea batatas (L.) Lam. Plant Cell Tissue Organ Cult 90: 265-273.

65. Jefferson RA, Kavangh TA, Bevan MW (1987) GUS fusions: $\beta$-glucuronidase as a sensitive and versatile gene fusion marker in higher plants. EMBO J 6: 3901-3907.

66. Gleave AP (1992) A versatile binary vector system with a T-DNA organizational structure conducive to efficient integration of cloned DNA into the plant genome. Plant Mol Biol 20: 1203-1207.

67. Bechtold N, Pelletier G (1998) In planta Agrobacterium mediated transformation of adult Arabidopsis thaliana plants by vacuum infiltration. Methods Mol Biol 82: 259-266.

68. Butenko MA, Patterson SE, Grini PE, Stenvik GE, Amundsen SS, et al. (2003) INFLORESCENCE DEFICIENT IN ABSCISSION controls floral organ abscission in Arabidopsis and identifies a novel family of putative ligands in plants. Plant Gell 15: 2296-2307. 
69. Gietz D, St Jean A, Woods RA, Schiestl RH (1992) Improved method for high efficiency transformation of intact yeast cells. Nucleic Acids Res 20: 1425.

70. Shinjyo C (1975) Genetical studies of cytoplasmic male sterility and fertility restoration in rice, Oryza sativa L. Sci Bull Coll Agric Univ Ryukyus 22: 1-51.

71. Wei WH, Li YC, Wang LJ, Liu SY, Yan XH, et al. (2010) Development of a novel Sinapis arvensis disomic addition line in Brassica napus containing the restorer gene for $\mathcal{N}_{s} a$ CMS and improved resistance to Sclerotinia sclerotiorum and pod shattering. Theor Appl Genet 120: 1089-1097.

72. Rao GU, Jain A, Shivanna KR (1992) Effects of high temperature stress on Brassica pollen: viability, germination and ability to set fruits and seeds. Annal Bot 69: 193-198.

73. Fujii S, Toriyama K (2005) Molecular mapping of the fertility restorer gene for ms-CW-type cytoplasmic male sterility of rice. Theor Appl Genet 111: 696-701.

74. Naito S, Dube PH, Beachy RN (1988) Differential expression of conglycinin $\alpha^{\prime}$ and $\beta$ subunit genes in transgenic plants. Plant Mol Biol 11: 109-123.
75. Laemmli UK (1970) Cleavage of structural proteins during the assembly of the head of Bacteriophage T4. Nature 227: 680-685.

76. Iida K, Seki M, Sakurai T, Satou M, Akiyama K, et al. (2005) RARTF: Database and tools for complete sets of Arabidopsis transcription factors. DNA Res 12: 247-256.

77. Tamura K, Peterson D, Peterson N, Stecher G, Nei M, et al. (2011) MEGA5: Molecular evolutionary genetics analysis using maximum likelihood, evolutionary distance, and maximum parsimony methods. Mol Biol Evol 28: 2731-2739.

78. Saitou N, Nei M (1987) The neighbor-joining method: a new method for reconstructing phylogenetic trees. Mol Biol Evol 4: 406-425.

79. Efron B, Halloran E, Holmes S (1996) Bootstrap confidence levels for phylogenetic trees. Proc Natl Acad Sci 93: 7085-7090.

80. Higgins JA, Bailey PC, Laurie DA (2010) Comparative genomics of flowering time pathways using Brachypodium distachyon as a model for the temperate grasses. PLoS one 19: e10065. 